\title{
Structure of the $\mathrm{NiFe}_{2} \mathrm{O}_{4}(001)$ surface in contact with gaseous $\mathrm{O}_{2}$ and water vapour
}

\author{
Xiao Shi $^{\dagger}$, Ye-Fei Li ${ }^{\dagger \ddagger}$, Steve L. Bernasek ${ }^{\dagger}$, and Annabella Selloni ${ }^{\dagger *}$
}

${ }^{\dagger}$ Department of Chemistry, Princeton University, Princeton, New Jersey 08544, United States

$\$$ Present address: Department of Chemistry, Fudan University, Shanghai, Shanghai 200433, China

\begin{abstract}
:
Nickel ferrite, $\mathrm{NiFe}_{2} \mathrm{O}_{4}$, is a material with interesting physical properties and useful technological applications. We have used Density-functional theory with on-site Coulomb repulsion U term to study the structure, electronic properties, and energetics of the $\mathrm{NiFe}_{2} \mathrm{O}_{4}(001)$ surface and its interaction with water both in the absence and in the presence of surface oxygen vacancies. In a humid environment, water adsorbs dissociatively on the surface oxygen vacancies leading to the formation of surface hydroxyls. At high temperature, water desorbs leaving a surface containing oxygen vacancies. These defects could represent useful reactive sites for various catalytic reactions.
\end{abstract}




\section{1- Introduction}

The spinel ferrites with general formula $A F e_{2} \mathrm{O}_{4}$ are materials of both fundamental and technological interest ${ }^{1}$. In particular, $\mathrm{NiFe}_{2} \mathrm{O}_{4}$ is a promising material for magnetic storage systems $^{2}$, magnetic-resonance imaging ${ }^{3}$, spintronics ${ }^{4,5}$, etc. Recently, $\mathrm{NiFe}_{2} \mathrm{O}_{4}$ has also attracted significant attention for its catalytic activity for the oxygen evolution reaction ${ }^{6}$, and as a potential catalyst for the Water Gas Shift (WGS) reaction ${ }^{7}$, where the reactivity is limited by water desorption ${ }^{8}$. The interaction of $\mathrm{NiFe}_{2} \mathrm{O}_{4}$ surfaces with water plays a key role in all the applications of this material in catalysis. Understanding this interaction is thus essential for the design of more efficient $\mathrm{NiFe}_{2} \mathrm{O}_{4}$ catalysts for the WGS and other oxidation reactions.

While numerous theoretical ${ }^{9}$ and experimental ${ }^{10-12}$ investigations of the bulk electronic and magnetic properties of $\mathrm{NiFe}_{2} \mathrm{O}_{4}$ have been reported, studies on the surfaces of $\mathrm{NiFe}_{2} \mathrm{O}_{4}$ are still scarce. $\mathrm{NiFe}_{2} \mathrm{O}_{4}$ exposes different surfaces depending on the growth and preparation conditions $^{11,12}$, the (111) and (001) surfaces being the most frequent ones. For instance, hydrothermal synthesis of $\mathrm{NiFe}_{2} \mathrm{O}_{4}$ nanoparticles often leads to faceted octahedra enclosed by (111) planes ${ }^{13}$, while films grown on $\mathrm{MgAl}_{2} \mathrm{O}_{4}$ or $\mathrm{SrTiO}_{3}$ expose the (001) surface ${ }^{11,12}$. Recently, DFT calculations have shown that $\mathrm{H}_{2} \mathrm{O}$ undergoes strong dissociative adsorption on the metal terminated (111) surface ${ }^{13}$. Instead, the structure of the (001) surface and its interaction with water have not yet been studied.

To help fill this gap, we present here a computational study of the structure of the $\mathrm{NiFe}_{2} \mathrm{O}_{4}(001)$ surface exposed to molecular oxygen and water vapour, the most common gases with which a surface can be in contact. Using the DFT $+U$ method, we start by studying the electronic density of states (DOS) of bulk $\mathrm{NiFe}_{2} \mathrm{O}_{4}$ both in the absence and in the presence of an oxygen vacancy. These results are used as a reference in order to understand the effects of the (001) termination on the electronic structure. We next study the adsorption of water on both the defect-free and defected $\mathrm{NiFe}_{2} \mathrm{O}_{4}(001)$ surfaces. Our computed surface stability diagram predicts that the $\mathrm{NiFe}_{2} \mathrm{O}_{4}(001)$ surface is hydroxylated at ambient conditions, while it exhibits surface oxygen vacancies in the temperature range of $600-900 \mathrm{~K}$ that is often used for catalytic reactions. 


\section{2- Methods and Models}

DFT calculations were performed within the plane-wave-pseudopotential scheme as implemented in the Quantum Espresso package ${ }^{14}$. Spin polarization was always included, and exchange and correlation terms were described using the gradient corrected Perdew-BurkeErnzerhof (PBE) ${ }^{15}$ functional with the on-site Coulomb repulsion $U$ term on the Fe and Ni $3 \mathrm{~d}$ states. We used the values $\mathrm{U}(\mathrm{Ni})=5.5 \mathrm{eV}$ and $\mathrm{U}(\mathrm{Fe})=3.5 \mathrm{eV}$ and $3.4 \mathrm{eV}$ for different $\mathrm{Fe}$ sites, which were determined from linear response ${ }^{16}$. Ultrasoft pseudopotentials ${ }^{17}$ were employed and the valence electrons included $\mathrm{O} 2 \mathrm{~s}, 2$ p; Fe 3 d, 4 s and Ni 3 d, 4 s states. Kinetic energy cutoffs of $50 \mathrm{Ry}$ and $500 \mathrm{Ry}$ were chosen for the wave functions and augmented density, respectively. Structural optimizations were carried out by relaxing all atomic positions until all forces were smaller than $1 \times 10^{-3}$ a.u.

Bulk calculations were performed using different unit cells. The lattice constant was determined using the 28-atom primitive cell (Figure 1a), with a $4 \times 4 \times 3$ Monkhorst-Pack k-point grid to sample the Brillouin zone. To model a bulk oxygen vacancy, we used the conventional cubic cell (Figure 1b) with one oxygen atom removed, and sampled the Brillouin zone with a $3 \times 3 \times$ 3 k-point grid.

As in previous studies of the surfaces of spinel oxides ${ }^{18-20}$, we modeled the $\mathrm{NiFe}_{2} \mathrm{O}_{4}(001)$ surface using symmetric slabs of 11 layers terminated by layers exposing oxygen and octahedral Fe and Ni sites. The slabs were separated by a vacuum region $20 \AA$ wide. To check the convergence of the slab thickness, we calculated the surface oxygen vacancy formation energy (see definition below) for slabs of different thicknesses; we found the formation energy difference between 11layer and 13-layer slabs to be less than $0.01 \mathrm{eV}$. We considered $1 \times 1$ square unit cell, which corresponds to the conventional cell. We sampled the surface Brillouin zone using a $3 \times 3 \times 1 \mathrm{k}$ point grid. Adsorption calculations and defected surface calculations were performed with adsorbed species and surface defects present on one side only of the slab (Model I). To validate this approach, we performed test calculations with adsorbed species and defects symmetrically present on both sides of the slab (Model II). We found that the two models predict very similar results. For instance, the computed surface oxygen vacancy formation energy at $\mathrm{T}=0 \mathrm{~K}$ is 0.342 $\mathrm{eV}$ with Model I and $0.366 \mathrm{eV}$ with Model II. Moreover, the value obtained for Model I changed by less than $0.01 \mathrm{eV}$ when dipole corrections were included. Similarly, water dissociation at the surface vacancy yields an energy gain of $1.026 \mathrm{eV}$ with Model I and $1.025 \mathrm{eV}$ with Model II. 
In order to study the surface phase diagram, we computed the formation energy $E_{F . E .}\left(T,\left\{p_{i}\right\},\left\{n_{i}\right\}\right)$ of the surface in contact with various gases at temperature $\mathrm{T}$ as follows: ${ }^{21}$

$$
E_{F . E .}\left(T,\left\{p_{i}\right\},\left\{n_{i}\right\}\right)=E_{\text {tot }}\left(\left\{n_{i}\right\}\right)-E_{P}-\sum_{g a s} n_{i} \times u_{i}\left(T, p_{i}\right)
$$

Here, $\left\{p_{i}\right\}$ are the partial pressures of the gaseous species (oxygen and water), $\left\{n_{i}\right\}$ are the corresponding numbers of adsorbed/desorbed molecules on/from the surface, $E_{t o t}\left(\left\{n_{i}\right\}\right)$ is the total energy of the slab with the adsorbed/desorbed species at $0 \mathrm{~K}$ (the $\mathrm{T}$-dependence of the chemical potential of the slab can be considered negligible), $E_{P}$ is the total energy of the clean pristine (defect-free) surface, and $u_{i}\left(T, p_{i}\right)$ is the chemical potential of gas species $\mathrm{i}$ at temperature $\mathrm{T}$ and pressure $p_{i}$. For the latter, the expression given in Ref. ${ }^{21}$ was used. The zero point energy (ZPE) contribution of molecular water and adsorbed water and hydroxide groups was included in the corresponding chemical potential and total energies.

As a special case of Eq. (1), the formation energy of an oxygen vacancy at $0 \mathrm{~K}$ and oxygen partial pressure of $1 \mathrm{~atm}$ was calculated using the expression $E_{F E}=E_{v a c}-E_{n o-d e f}-\frac{1}{2} E_{O_{2}}$, where $E_{v a c}$ and $E_{n o-d e f}$ denote the total energies of the systems with and without vacancy, respectively.

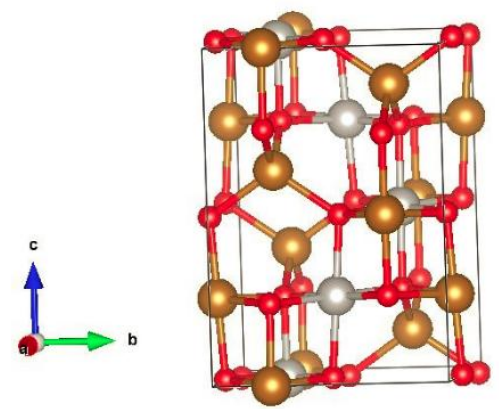

(a)

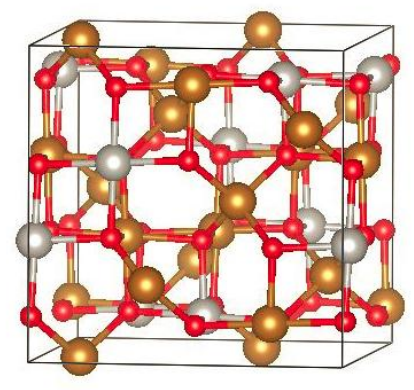

(b)

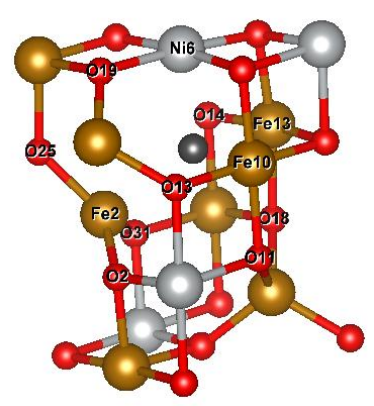

(c)

Fig 1. Primitive cell (a), and conventional cell (b), of the $\alpha$-type inverse spinel crystal structure of $\mathrm{NiFe}_{2} \mathrm{O}_{4}$. (c) Local structure of an oxygen vacancy (black sphere) in the conventional cell, with different atoms labeled as in Table 1. Red, gray and yellow spheres represent oxygen, $\mathrm{Ni}$, and $\mathrm{Fe}$ atoms, respectively. 


\section{3- Results and Discussion}

\subsection{Bulk properties}

$\mathrm{NiFe}_{2} \mathrm{O}_{4}$ crystallizes in the $\alpha$ type inverse spinel (Figure 1a), which has a tetragonal $\mathrm{P} 4_{1} 22 / \mathrm{P}_{3} 22$ symmetry $^{22}$. Equal numbers of $\mathrm{Ni}$ and Fe atoms occupy octahedral sites, while the remaining $\mathrm{Fe}$ atoms occupy tetrahedral sites. The conventional cell (Figure 1b) is a $\sqrt{2} \times \sqrt{2} \times 1$ primitive cell having 8 formula units. The lattice constant was determined by fitting the computed total energies to the Birch-Burnagham equation of state. We obtained a value of $8.45 \AA$, which is about $1.4 \%$ larger than the experimental value of $8.33 \AA .^{23}$

The computed DOS for the defect-free crystal (Figure 2a) shows an overall band gap of $1.0 \mathrm{eV}$. The band gap is $1.5 \mathrm{eV}$ for the majority bands (spin up) and $1.6 \mathrm{eV}$ for the minority bands, in good agreement with the experimental value of the optical band gap of $1.6 \mathrm{eV}^{24}$ Also in agreement with experiment ${ }^{10,24}$, we find $\mathrm{NiFe}_{2} \mathrm{O}_{4}$ to be ferrimagnetic, the octahedral $(\mathrm{Oh})$ and tetrahedral (Td) sites being occupied predominantly by majority and minority spins, respectively. The oxidation states of the metal ions, computed using the method in Ref. ${ }^{25}$, are $2+$ for Ni and $3+$ for Fe.

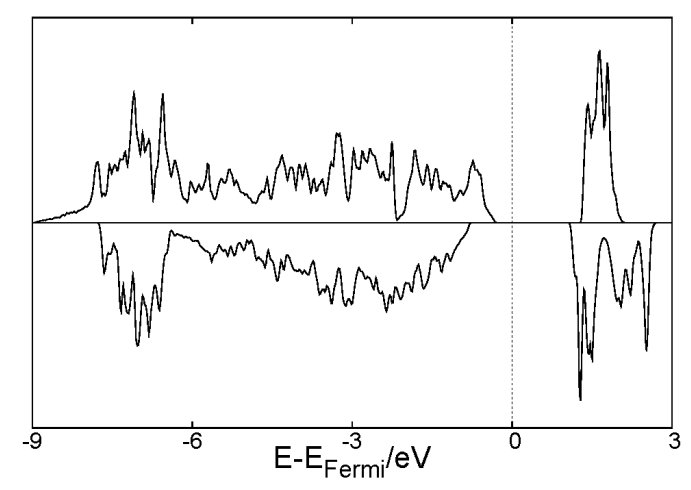

(a)

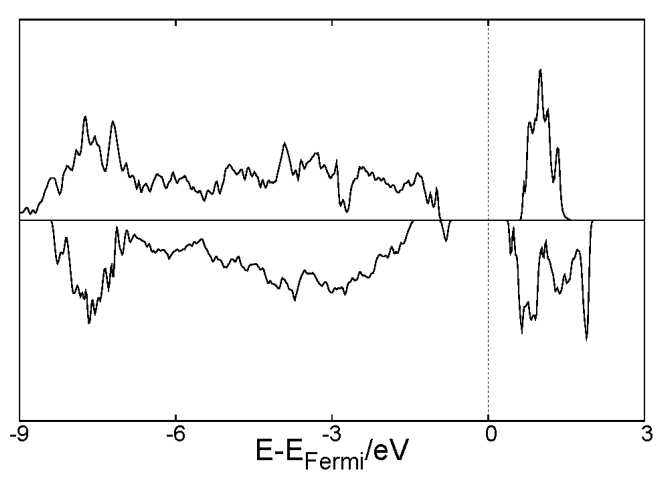

(b)

Fig 2. Density of states for: (a) defect-free bulk $\mathrm{NiFe}_{2} \mathrm{O}_{4}$; (b) defective crystal with an oxygen vacancy (Fig 1c).

As most oxidation reactions on metal oxides occur through a Mars-van Krevelen mechanism, the oxygen vacancy formation energy is usually considered a good descriptor of the reactivity of these materials ${ }^{26}$. $\mathrm{NiFe}_{2} \mathrm{O}_{4}$ contains two inequivalent oxygen anions: $\mathrm{O}_{\mathrm{I}}$, bound to $2 \mathrm{Fe}$ and $1 \mathrm{Ni}$ 
at $\mathrm{Oh}$ sites and $1 \mathrm{Fe}$ at $\mathrm{Td}$, and $\mathrm{O}_{\mathrm{II}}$, bound to $1 \mathrm{Fe}$ and $2 \mathrm{Ni}$ at $\mathrm{Oh}$ sites and $1 \mathrm{Fe}$ at $\mathrm{Td}$. We found that an $\mathrm{O}_{\mathrm{I}}$ vacancy is slightly preferred (less costly) with respect to an $\mathrm{O}_{\mathrm{II}}$ one. Still, the computed formation energy, $2.87 \mathrm{eV}$, is rather high indicating that one may need high vacuum and high temperatures to create oxygen vacancies in bulk $\mathrm{NiFe}_{2} \mathrm{O}_{4}$. For comparison, we also computed the oxygen vacancy formation energy in $\mathrm{Co}_{3} \mathrm{O}_{4}$, another well-studied spinel oxide, using DFT+U with $\mathrm{U}=4.4$ and $6.6 \mathrm{eV}$ for $\mathrm{Co}$ ions at $\mathrm{Td}$ and $\mathrm{Oh}$ sites, respectively ${ }^{27}$. The resulting value, $2.88 \mathrm{eV}$, is very similar to that found for $\mathrm{NiFe}_{2} \mathrm{O}_{4}$.

The displacements of several atoms around the oxygen vacancy are reported in Table 1. Fe2, the $\mathrm{Fe}(\mathrm{Td})$ cation closest to the oxygen vacancy (which was originally bonded to the removed $\mathrm{O}$ atom), undergoes a large displacement, $0.46 \AA$, with respect to its position in the defect-free crystal. Large displacements of about $0.1 \AA$ are present also for a few oxygens $(\mathrm{O} 2, \mathrm{O} 25$ and O31) bonded to Fe2. The electronic DOS for the defective crystal is shown in Figure $2 b$. We can see that the DOS for the majority spin states is little affected by the O-vacancy, whereas additional bands are present for the minority spin states, in particular a new occupied state above the original minority band valence band maximum. This results in a smaller minority band gap of $\sim 1.0 \mathrm{eV}$. At the same time, the Fermi levels moves up in the band gap consistent with the fact that the O-vacancy is an electron donor. Analysis of the spin and charge distribution further shows that one of the two excess electrons donated by the $\mathrm{O}$-vacancy reduces the oxidation state of the neighboring $\mathrm{Fe} 2(\mathrm{Td})$ cation from $3+$ to $2+$, and at the same time reduces also its magnetic moment. The other excess electron is shared by the three neighboring Fe10, Fe13 and Ni6 cations at Oh sites and slightly reduces their magnetic moments. Since Td and Oh sites have different spin states, the total magnetization remains unchanged in the presence of the O-vacancy. 
Table 1. Displacements of the atoms close to a bulk O-vacancy (Figure 1c) with respect to their positions in the defect-free crystal (Figure 1b). Atoms are labelled as in Figure 1c. Only the atoms closest to the vacancy are considered.

\begin{tabular}{|c|c|c|c|}
\hline & \multicolumn{3}{|c|}{ Displacement $(\AA \stackrel{\AA}{)})$} \\
\hline & $\mathbf{x}$ & $\mathbf{y}$ & $\mathbf{Z}$ \\
\hline $\mathbf{O 2}$ & 0.071 & -0.044 & -0.048 \\
\hline 011 & 0.008 & 0.044 & 0.045 \\
\hline 013 & -0.041 & 0.005 & 0.053 \\
\hline 014 & 0.051 & 0.012 & -0.047 \\
\hline 018 & 0.057 & 0.054 & -0.001 \\
\hline 019 & -0.033 & -0.011 & -0.004 \\
\hline $\mathbf{O 2 5}$ & 0.077 & 0.055 & 0.075 \\
\hline 031 & -0.025 & -0.052 & 0.056 \\
\hline $\mathrm{Fe} 2$ & 0.281 & -0.242 & 0.273 \\
\hline Fe10 & -0.029 & 0.021 & -0.009 \\
\hline Fe13 & -0.036 & 0.021 & -0.033 \\
\hline Ni6 & -0.010 & 0.060 & -0.017 \\
\hline
\end{tabular}

\section{$3.2 \mathrm{NiFe}_{2} \mathrm{O}_{4}(001)$ surface}

\section{(a) Defect-free surface}

The optimized structure of the $\mathrm{NiFe}_{2} \mathrm{O}_{4}(001)$ surface is shown in Figure 3, while the atomic displacements relative to the positions of the bulk-terminated surface are reported in Table 2 . We can see significant outward displacements of the atoms in the first three layers in comparison to the positions of the bulk-terminated surface. Particularly large $(>0.1 \AA)$ displacements along the [001] direction are present for $\mathrm{Fe} 2(\mathrm{Td})$ in the second layer, and for $\mathrm{O} 2, \mathrm{O} 3, \mathrm{O} 4$ in the top three layers. Large in plane displacements are also present for $\mathrm{O} 2$ and $\mathrm{O} 3$, the surface oxygens that are not bonded to $\mathrm{Fe} 2$. 


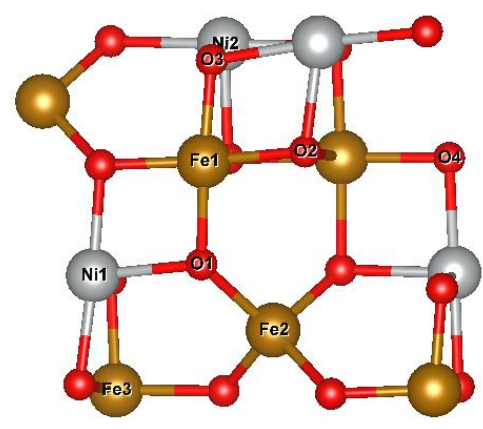

(a)

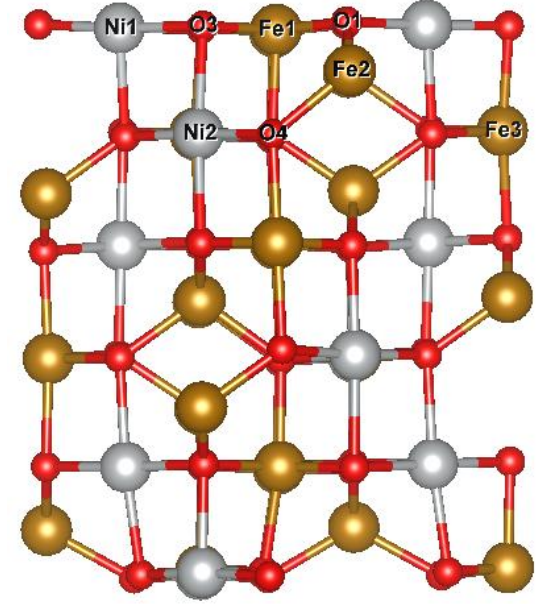

(b)

Fig 3. Structure of the $\mathrm{NiFe}_{2} \mathrm{O}_{4}$ (001) surface: (a) top view of the top three layers, and (b) side view. Various $\mathrm{O}, \mathrm{Fe}$ and $\mathrm{Ni}$ atoms are indicated.

Table 2. Displacements of the atoms in the first three layers of the relaxed (001) surface relative to their positions at the bulk-terminated surface

\begin{tabular}{lll}
\hline $\begin{array}{l}\text { displacement } \\
\text { A }\end{array}$ & in plane & $(\mathbf{0 0 1})$ direction \\
\hline $\mathrm{O} 1$ & & \\
$\mathrm{O} 2$ & 0.098 & 0.026 \\
$\mathrm{O} 3$ & 0.185 & 0.126 \\
$\mathrm{O} 4$ & 0.185 & 0.080 \\
$\mathrm{Ni} 1$ & 0.085 & 0.108 \\
$\mathrm{Ni} 2$ & 0.026 & 0.024 \\
$\mathrm{Fe} 1$ & 0.017 & 0.062 \\
$\mathrm{Fe} 2$ & 0.049 & 0.036 \\
$\mathrm{Fe} 3$ & 0.042 & 0.196 \\
\hline
\end{tabular}

The DOS (Figure 4a) for the defect-free $\mathrm{NiFe}_{2} \mathrm{O}_{4}(001)$ surface shows the formation of surface states in the band gap of the majority spin DOS which make the surface metallic. An analogous result was found for the $\mathrm{Co}_{3} \mathrm{O}_{4}(110)$ surface. ${ }^{18}$ By contrast, the minority spin band is almost unaffected by the presence of the surface and remains very similar to the minority spin band in 
the bulk. The computed work function was determined from the analysis of the electrostatic potential profile, and found to have a value of about $6 \mathrm{eV}$.

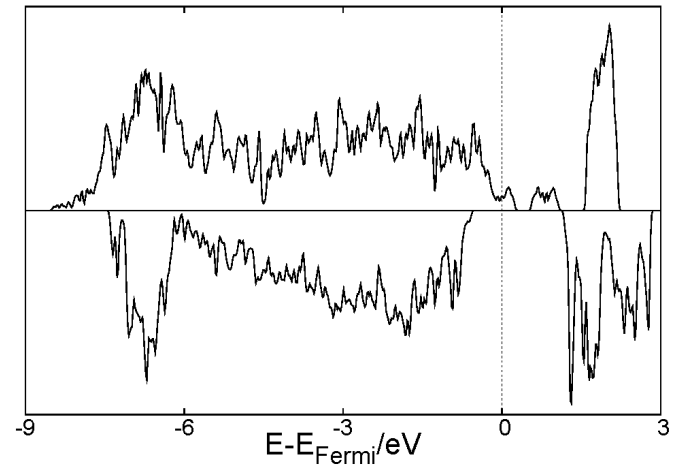

(a)

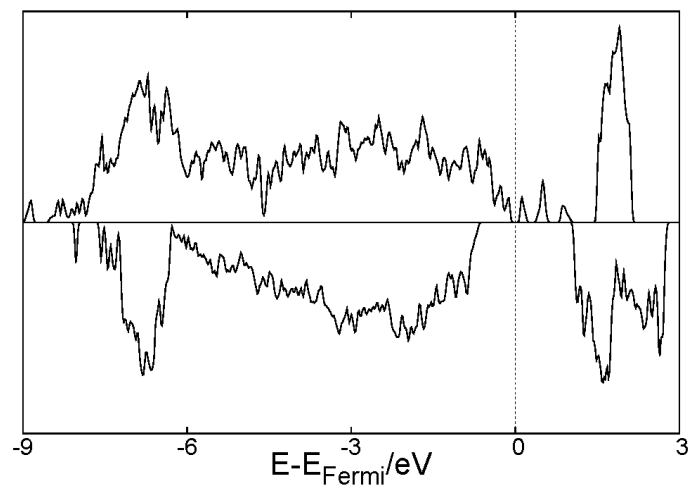

(c)

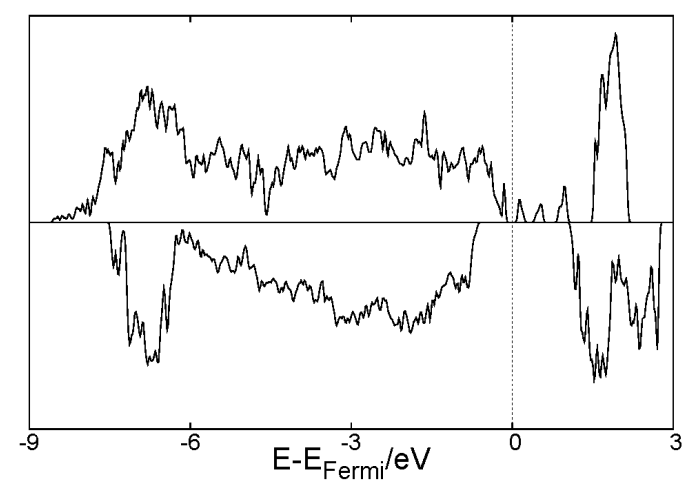

(b)

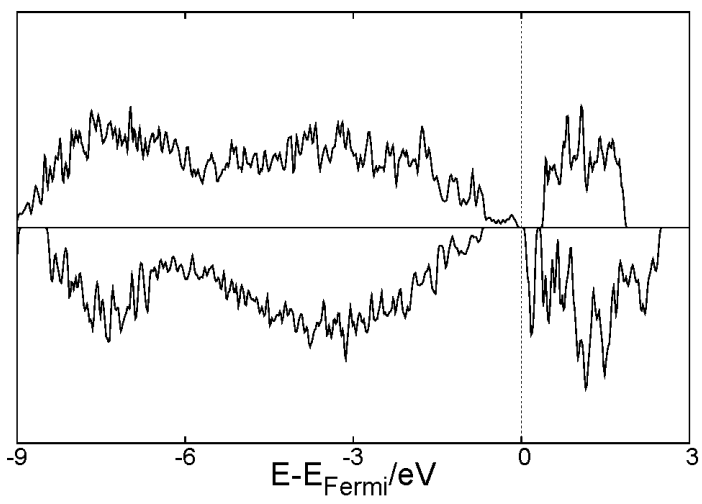

(d)

Fig 4. DOS for: (a) clean defect-free $\mathrm{NiFe}_{2} \mathrm{O}_{4}(001)$ (denoted as $\mathrm{P}$ ); (b) clean surface with 1 oxygen vacancy/unit cell $\left(\mathrm{P}+1 \mathrm{~V}_{\mathrm{O}}\right)$; (c) hydroxylated surface resulting from the adsorption of 1 water molecule/unitcell on the surface in (b) $\left(\mathrm{P}+1 \mathrm{~V}_{\mathrm{O}}+1 \mathrm{H}_{2} \mathrm{O}\right)$; (d) fully water-covered surface resulting from the adsorption of 6 water molecules/unit cell on the surface with $25 \%$ concentration of oxygen vacancies $\left(\mathrm{P}+2 \mathrm{~V}_{\mathrm{O}}+6 \mathrm{H}_{2} \mathrm{O}\right)$

\section{(b) Surface O vacancy}

To determine the preferred structure of $\mathrm{NiFe}_{2} \mathrm{O}_{4}(001)$, we studied the formation of 1 and 2 surface oxygen vacancies ( $\mathrm{V}_{\mathrm{O}}$ 's) per unit cell, corresponding to surface $\mathrm{V}_{\mathrm{O}}$ concentrations of $1 / 8$ (Figure 5a) and 1/4 (Figure 5b), respectively. The formation of $1 \mathrm{~V}_{\mathrm{O}} /$ unit cell has an energy cost of $0.34 \mathrm{eV}$ at $0 \mathrm{~K}$ and 1 atm $\mathrm{O}_{2}$ pressure. The most favorable site for $\mathrm{V}_{\mathrm{O}}$ formation is the $\mathrm{O} 3$ site, i.e. the oxygen that bonds to two Ni cations (Ni1 and $\mathrm{Ni} 2$ ) and one $\mathrm{Fe}(\mathrm{Fe} 1)$. By comparing to the bulk formation energy of $2.87 \mathrm{eV}$, it is clear that creating an oxygen vacancy at the surface 
is much easier than in the bulk. This remains true also at higher $\mathrm{V}_{O}$ concentrations, even though the $V_{O}$ formation energy increases significantly with increasing concentration. The formation of 2 oxygen vacancies per unit cell (Figure 5b) has indeed an energy cost of $1.43 \mathrm{eV}$, which corresponds to an average formation energy of $0.71 \mathrm{eV}$ per vacancy. The two oxygen vacancies prefer to form both at $\mathrm{O} 3$ sites, and all $\mathrm{O} 3$ anions are removed by forming 2 oxygen vacancies /unit cell. Formation of the second oxygen vacancy at $\mathrm{O} 2$, which binds to $2 \mathrm{Fe}(\mathrm{Oh})$ site and 1 $\mathrm{Ni}(\mathrm{Oh})$, has a slightly higher energy cost than at the $\mathrm{O} 3$ site, whereas $\mathrm{O} 1$ is much harder to remove. Since O1 binds to $\mathrm{Fe} 2(\mathrm{Td})$, removing O1 would indeed result in a undercoordinated $\mathrm{Fe}(\mathrm{Td})$ which is much more unstable.

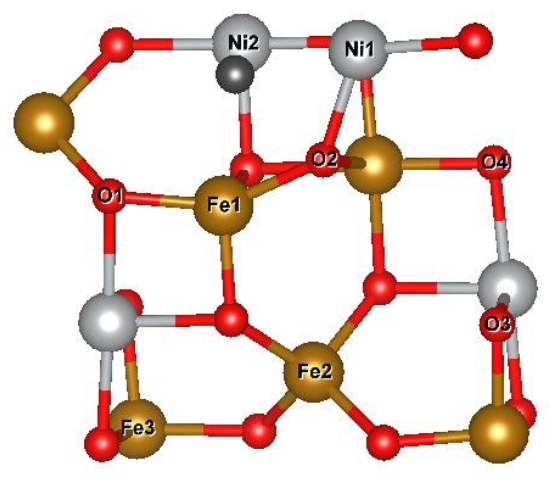

(a)

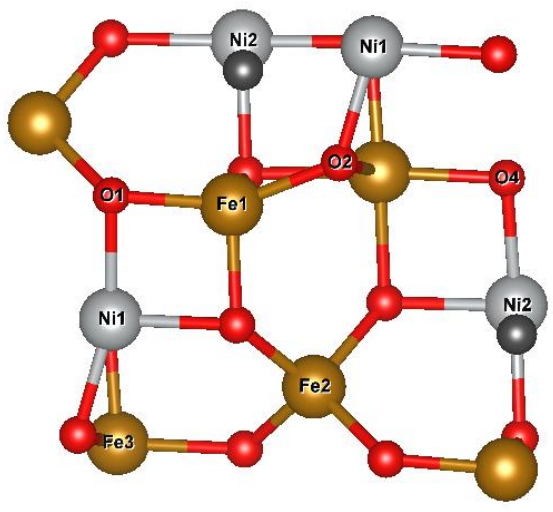

(b)

Fig 5. Top views of the first three layers of the $\mathrm{NiFe}_{2} \mathrm{O}_{4}(001)$ surface in the presence of (a) $1 \mathrm{O}$-vacancy $\left(\mathrm{P}+1 \mathrm{~V}_{\mathrm{O}}\right)$ (b) $2 \mathrm{O}$-vacancies $\left(\mathrm{P}+2 \mathrm{~V}_{\mathrm{O}}\right)$. The oxygen vacancies are indicated by the black spheres. Atoms are labelled as in Figure 3.

The DOS for the surface with $1 / 8 \mathrm{~V}_{\mathrm{O}}$ coverage is shown in Figure $4 \mathrm{~b}$. We can see a change in the majority spin surface state band, which results in the opening of a narrow band gap of $\sim 0.1 \mathrm{eV}$ at the Fermi level. On the other hand, the minority spin band does not change significantly except for a small increase, by $0.1 \mathrm{eV}$, of the band gap. The computed work function, $5.9 \mathrm{eV}$, remains almost unchanged relative to the one for the pristine surface.

\subsection{Water adsorption.}

\section{(a) Water adsorption on the defect-free surface}

The adsorption structures of water on the pristine $\mathrm{NiFe}_{2} \mathrm{O}_{4}(001)$ surface are found to vary significantly with coverage. At $1 / 4$ mono-layer (ML) coverage, corresponding to 1 water 
molecule per surface cell (Figure 5a), water adsorbs in molecular form on a Ni cation, whereas it dissociates on $\mathrm{Fe}$, resulting in an $\mathrm{OH}$ on top of the $\mathrm{Fe}$ ion and an $\mathrm{H}$ donated to a surface oxygen. The adsorption energy on $\mathrm{Ni}$ is $0.53 \mathrm{eV}$, which is about $0.1 \mathrm{eV}$ more favorable that on Fe. At $1 / 2$ ML coverage (Figure 5b), the two water molecules prefer to adsorb both in molecular form, one on a $\mathrm{Ni}$ site and one on a Fe site, with an adsorption energy of $0.44 \mathrm{eV} / \mathrm{H}_{2} \mathrm{O}$. At $3 / 4 \mathrm{ML}$ coverage (Figure 5c), the most stable configuration corresponds to two water molecules adsorbed in molecular form on $\mathrm{Ni}$ sites and one dissociated water on a Fe site, and the adsorption energy is $0.58 \mathrm{eV} / \mathrm{H}_{2} \mathrm{O}$. Finally, the preferred configuration at full water coverage has all the 4 water molecules adsorbed in molecular form (Figure 5d): two on $\mathrm{Ni}$, one on $\mathrm{Fe}$ and one forming an $\mathrm{H}$ bond with an $\mathrm{O}$ site, with average adsorption energy of $0.52 \mathrm{eV} / \mathrm{H}_{2} \mathrm{O}$. A mixed moleculardissociated structure with two intact and two dissociated water molecules adsorbed on $\mathrm{Ni}$ and $\mathrm{Fe}$ sites, respectively, was found to be slightly higher in energy.
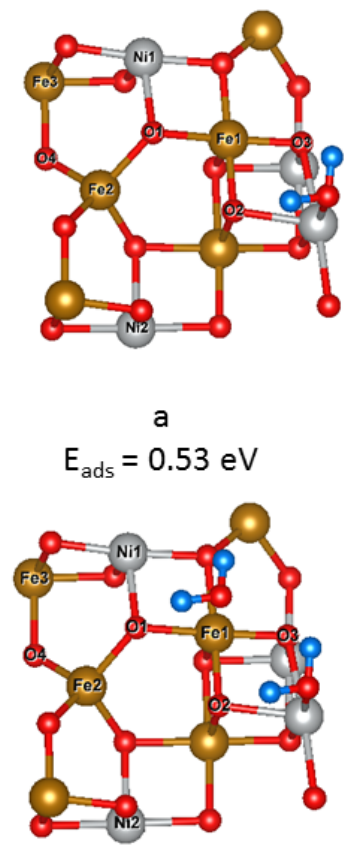

b

$E_{a d s}=0.44 \mathrm{eV}$
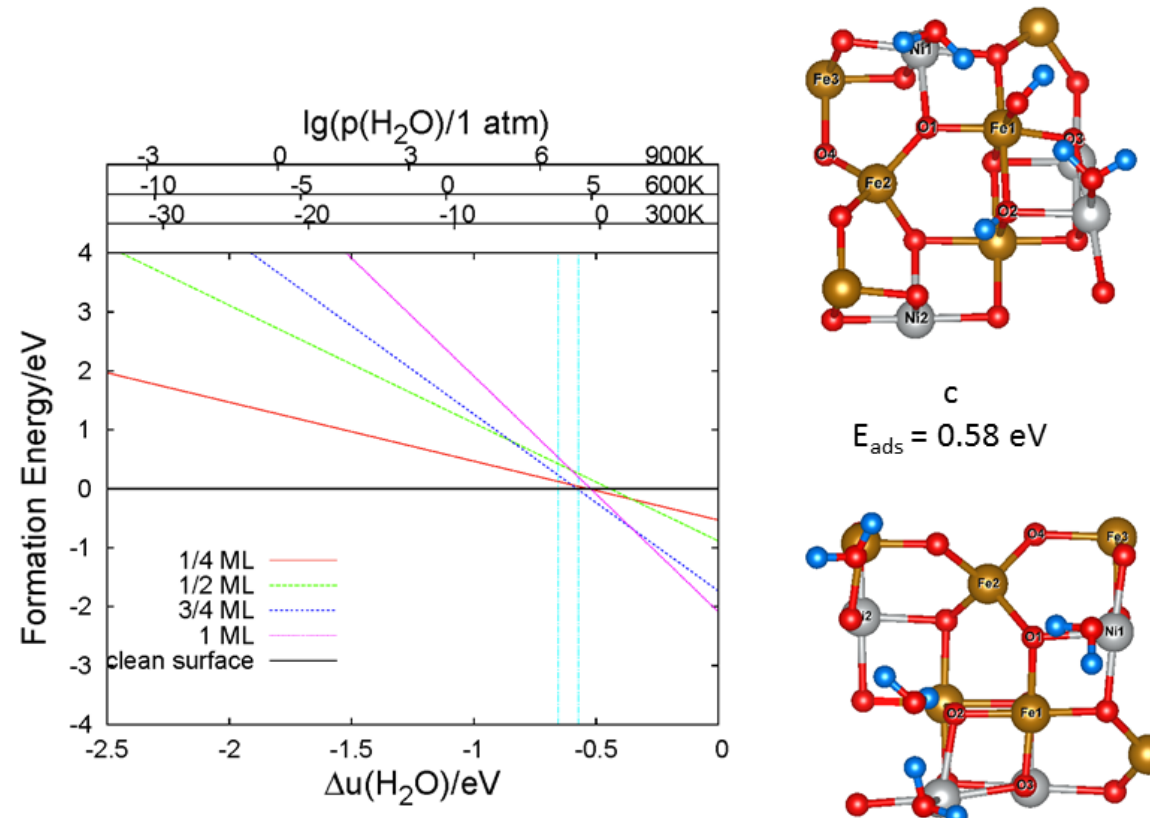

$c$ $E_{\text {ads }}=0.58 \mathrm{eV}$

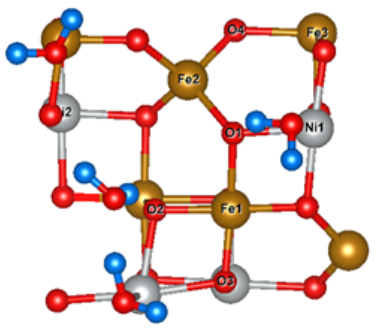

d $E_{\text {ads }}=0.52 \mathrm{eV}$

Fig 6. Phase diagram of pristine $\mathrm{NiFe}_{2} \mathrm{O}_{4}$ (001) exposed to water vapour. The two vertical lines in cyan indicate the region of water chemical potential corresponding to liquid water ( $300 \mathrm{~K}-400 \mathrm{~K}$ ). The side panels show the structures of adsorbed water at different coverages (top views). (a) $1 / 4 \mathrm{ML}$, (b) $1 / 2 \mathrm{ML}$, (c) 3/4 ML, (d) 1 ML. Reported adsorption energies include the change of zero point energies. 
The phase diagram for the pristine surface exposed to water is shown in Figure 6. This was obtained by considering the dependence of the computed surface formation energies on the water chemical potential $\Delta u_{\mathrm{H}_{2} \mathrm{O}}\left(T, p_{\mathrm{H}_{2} \mathrm{O}}\right)=u_{\mathrm{H}_{2} \mathrm{O}}\left(T, p_{\mathrm{H}_{2} \mathrm{O}}\right)-E_{\mathrm{H}_{2} \mathrm{O}}$, where $\mathrm{E}_{\mathrm{H} 2 \mathrm{O}}$ denotes the total energy (including ZPE) of a water molecule at $\mathrm{T}=0 \mathrm{~K}$. This diagram predicts that all water desorbs from the pristine surface at temperatures above $\sim 300 \mathrm{~K}$.

\section{(b) Water adsorption on the defected surface}

Figure 7 shows some adsorption structures of water on defected $\mathrm{NiFe}_{2} \mathrm{O}_{4}(001)$ surfaces at various coverages. From the reported adsorption energies (Eads), we can see that water adsorption is much more favorable on the defected surface than on the pristine surface (Figure 6). In the presence of a surface oxygen vacancy (Figure 5a, structure $\mathrm{P}+1 \mathrm{Vo}$ ), a water molecule dissociates on the $\mathrm{V}_{\mathrm{O}}$ giving rise to two surface hydroxyls with Eads $=0.90 \mathrm{eV}$ (Figure 7a, structure $\mathrm{P}+1 \mathrm{Vo}+1 \mathrm{H}_{2} \mathrm{O}$ ). By adsorbing three additional water molecules to this structure, the water molecule adsorbed on the Fe site dissociates into $\mathrm{OH}$ groups while the other two molecules at $\mathrm{Ni}$ sites remain intact (Figure $7 \mathrm{~b}, \mathrm{P}+1 \mathrm{Vo}+4 \mathrm{H}_{2} \mathrm{O}$ ). The average adsorption energy per molecule is $0.70 \mathrm{eV}$, which is smaller than the value for a single water molecule in Figure $7 \mathrm{a}$. On the surface with two oxygen vacancies $(\mathrm{P}+2 \mathrm{Vo})$, the configuration with two water molecules adsorbed dissociatively on the two $\mathrm{V}_{\mathrm{O}}$ 's gives the highest adsorption energy, $1.23 \mathrm{eV} / \mathrm{molecule}$ (structure $\mathrm{P}+2 \mathrm{Vo}+2 \mathrm{H}_{2} \mathrm{O}$, Figure $7 \mathrm{c}$ ). When two additional water molecules are adsorbed on this surface, one prefers to adsorb in molecular form on a Ni site, while the other is dissociatively adsorbed on a Fe site(Figure $\left.7 \mathrm{~d}, \mathrm{P}+2 \mathrm{Vo}+4 \mathrm{H}_{2} \mathrm{O}\right)$. The adsorption energy, $0.86 \mathrm{eV} / \mathrm{molecule}$, is lower compared to Figure 7c but still quite higher than water adsorbed on the pristine surface. Finally, the addition of two further water molecules leads to a configuration where all metal sites are covered by adsorbed water (Figure $7 \mathrm{e}, \mathrm{P}+2 \mathrm{Vo}+6 \mathrm{H}_{2} \mathrm{O}$ ). The two added molecules dissociate on $\mathrm{Fe} 1$ sites and the average adsorption energy is $0.72 \mathrm{eV} / \mathrm{molecule}$. Altogether, it appears that mixed molecular-dissociated configurations are favored at high coverages. Water dissociation takes place both at oxygen vacancies and at Fe sites, whereas adsorption in molecular form is preferred at Ni sites. 
(a)

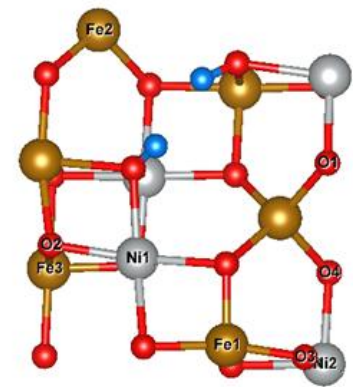

(b)

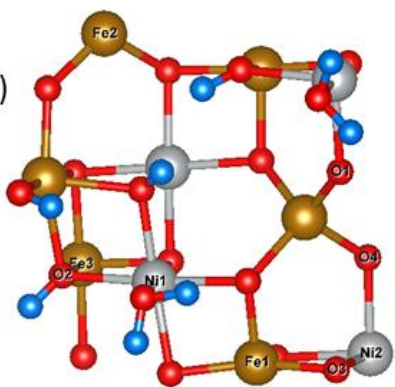

$E_{\text {ads }}=0.90 \mathrm{eV}$

$$
E_{\text {ads }}=0.70 \mathrm{eV}
$$

(c)

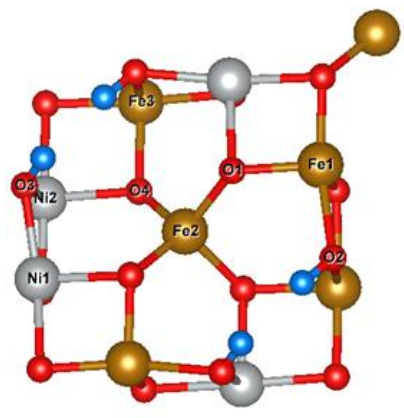

$E_{\text {ads }}=1.23 \mathrm{eV}$ (d)

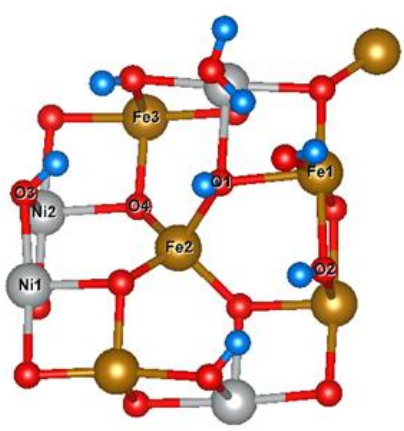

$E_{\text {ads }}=0.86 \mathrm{eV}$ (e)

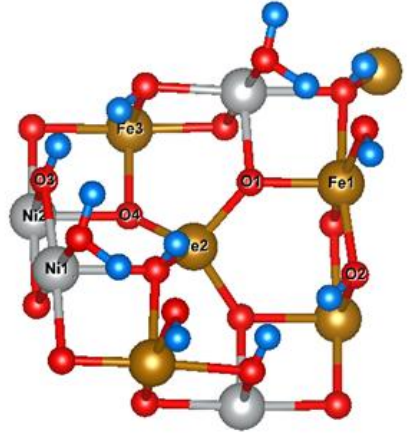

$E_{\text {ads }}=0.72 \mathrm{eV}$

Fig 7. Adsorption structures (top views) of water on defected $\mathrm{NiFe}_{2} \mathrm{O}_{4}(001)$ surfaces at different coverages: (a) one water molecule adsorbed to a surface with 1 oxygen vacancy $\left(\mathrm{P}+1 \mathrm{~V}_{\mathrm{O}}+1 \mathrm{H}_{2} \mathrm{O}\right)$, (b) four water molecules adsorbed to a surface containing 1 oxygen vacancy $\left(\mathrm{P}+1 \mathrm{~V}_{\mathrm{O}}+4 \mathrm{H}_{2} \mathrm{O}\right)$, (c) two water molecules adsorbed to two oxygen vacancies $\left(\mathrm{P}+2 \mathrm{~V}_{\mathrm{O}}+2 \mathrm{H}_{2} \mathrm{O}\right)$, (d) four water molecules adsorbed to a surface containing 2 oxygen vacancies $\left(\mathrm{P}+2 \mathrm{~V}_{\mathrm{O}}+4 \mathrm{H}_{2} \mathrm{O}\right)$, (e) six water molecules adsorbed to a surface with two oxygen vacancies $\left(\mathrm{P}+2 \mathrm{~V}_{\mathrm{O}}+6 \mathrm{H}_{2} \mathrm{O}\right)$. All structures shown refer to a single surface cell. Reported adsorption energies per molecule include $\mathrm{ZPE}$ corrections.

The DOS for the surface with an adsorbed water molecule at an oxygen vacancy site (Figure 4c) is very similar to that of the bare surface with the $V_{O}$ (Figure $4 b$ ). Analysis of the surface metal oxidation states shows that also these oxidation states remain unchanged upon water adsorption. Altogether, this indicates that the influence of adsorbed water on the surface electronic structure is rather limited. Support for this conclusion is also provided by the DOS for the fully hydrated surface (Figure 7e), which is shown in Figure 4d. Comparison to the DOS in Figure 4b and 4c for the clean defective and hydroxylated surfaces indicates that the main effect of the adsorbed water is the presence of additional bands for both spin states in the band gap near the Fermi level. 


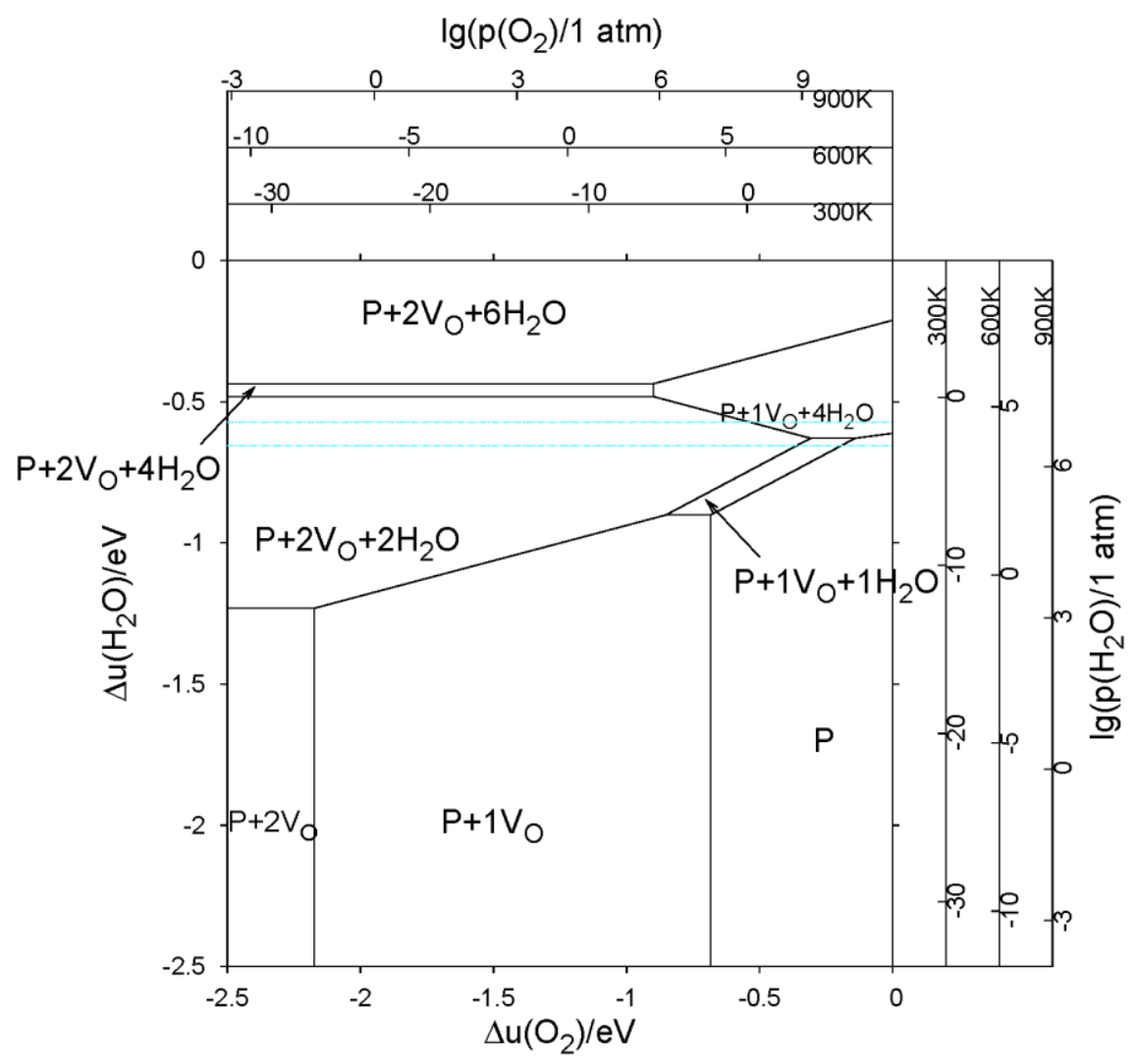

Fig 8. Phase diagram of $\mathrm{NiFe}_{2} \mathrm{O}_{4}(001)$ exposed to $\mathrm{H}_{2} \mathrm{O}$ and $\mathrm{O}_{2}$, as a function of the relative chemical potentials $\Delta u_{i}\left(T, p_{i}\right)=u_{i}\left(T, p_{i}\right)-E_{i}$ referred to the their values at $\mathrm{T}=0 \mathrm{~K}$. The two horizontal lines in cyan indicate the region of water chemical potential corresponding to liquid water. $\mathrm{P}$ in the phase diagram indicates the pristine (001) surface.

\subsection{Phase diagram}

In order to characterize the stability of the (001) surface in $\mathrm{O}_{2}$ and water vapour environment, we examined about 30 surface configurations without and with adsorbed water and used them to determine the stability diagram of the $\mathrm{NiFe}_{2} \mathrm{O}_{4}(001)$ surface in $\mathrm{O}_{2}$ and water vapor environment. The resulting diagram is shown in Figure 8. We identified eight favored structures in the relevant range of water and oxygen chemical potentials. Among these, two structures, i.e. $\mathrm{P}+1 \mathrm{~V}_{\mathrm{O}}$ and $\mathrm{P}+2 \mathrm{~V}_{\mathrm{O}}+2 \mathrm{H}_{2} \mathrm{O}$, are more prominent. In a wide range of conditions including ambient conditions, the $\mathrm{P}+2 \mathrm{~V}_{\mathrm{O}}+2 \mathrm{H}_{2} \mathrm{O}$ structure, corresponding to a surface with $\sim 25 \%$ of hydroxyls, is predicted to occur. At higher temperatures, water desorbs and a dry surface with oxygen vacancies ( 12\% 
concentration) becomes more favorable. The latter structure may be the one which is typically present during catalytic reactions like the WGS and the CO oxidation reactions.

\section{4 - Summary and Conclusions}

We have studied the atomic structure, electronic properties, and reactivity of the bulk and (001) surface of $\mathrm{NiFe}_{2} \mathrm{O}_{4}$ using the $\mathrm{PBE}+\mathrm{U}$ method. Our results show that, unlike in the bulk, oxygen vacancies form quite easily on the nickel ferrite surface, especially at oxygen sites that are coordinated mainly to $\mathrm{Ni}$ ions. Our results also indicate that dissociative adsorption of water at vacancy sites is much more favorable than adsorption at regular surface sites thus suggesting that a humid environment may help the creation of oxygen vacancies. From our computed surface phase diagram we infer that the $\mathrm{NiFe}_{2} \mathrm{O}_{4}(001)$ is hydroxylated at ambient conditions, while water desorption should lead to a defective surface containing a significant fraction of oxygen vacancies at higher temperature.

It is also interesting to notice that our computed phase diagram for $\mathrm{NiFe}_{2} \mathrm{O}_{4}(001)$ in Figure 8 is significantly different from that for the $\mathrm{Fe}_{3} \mathrm{O}_{4}(001)$ surface ${ }^{28}$ exposed to water and oxygen, despite the similarity of the two surfaces. In comparison to $\mathrm{NiFe}_{2} \mathrm{O}_{4}(001)$, the $\mathrm{Fe}_{3} \mathrm{O}_{4}(001)$

surface shows a stronger tendency to adsorb water whereas formation of an oxygen vacancy appears to be much more difficult. Due to its tendency to easily form surface oxygen vacancies, the $\mathrm{NiFe}_{2} \mathrm{O}_{4}$ (001) surface should be a promising catalyst material for oxidation reactions occurring through the Mars-Van Krevelen mechanism.

\section{Acknowledgments}

This work was supported by DoE-BES, Division of Chemical Sciences, Geosciences and Biosciences under Award DE-FG02-12ER16286. SLB acknowledges support from NSFCHE1213216. We used resources of the National Energy Research Scientific Computing Center (DoE Contract No. DE-AC02-05CH11231), and of the Center for Functional Nanomaterials at Brookhaven National Laboratory. We also acknowledge use of the TIGRESS high performance computer center at Princeton University. 


\section{References}

(1) Brabers, V. A. M.: Chapter 3 Progress in spinel ferrite research. 1995, 8, 189-324.

(2) Han, D.-H.; Luo, H.-L.; Yang, Z.: Remanent and anisotropic switching field distribution of platelike Ba-ferrite and acicular particulate recording media. Journal of Magnetism and Magnetic Materials 1996, 161, 376-378.

(3) Cunningham, C. H.; Arai, T.; Yang, P. C.; McConnell, M. V.; Pauly, J. M.; Conolly, S. M.: Positive contrast magnetic resonance imaging of cells labeled with magnetic nanoparticles. Magnetic Resonance in Medicine 2005, 53, 999-1005.

(4) Worledge, D. C.; Geballe, T. H.: Magnetoresistive double spin filter tunnel junction. Journal of Applied Physics 2000, 88, 5277.

(5) Hu, G.; Suzuki, Y.: Negative Spin Polarization of Fe3O4 in Magnetite/Manganite-Based Junctions. Physical Review Letters 2002, 89.

(6) Hong, D.; Yamada, Y.; Nagatomi, T.; Takai, Y.; Fukuzumi, S.: Catalysis of Nickel Ferrite for Photocatalytic Water Oxidation Using [Ru(bpy)3]2+and S2O82-. Journal of the American Chemical Society 2012, 134, 19572-19575.

(7) Reddy, G. K.; Gunasekera, K.; Boolchand, P.; Dong, J.; Smirniotis, P. G.: High Temperature Water Gas Shift Reaction over Nanocrystalline Copper Codoped-Modified Ferrites. The Journal of Physical Chemistry C 2011, 115, 7586-7595.

(8) Zhou, C.; Zhang, Q.; Chen, L.; Han, B.; Ni, G.; Wu, J.; Garg, D.; Cheng, H.: Density Functional Theory Study of Water Dissociative Chemisorption on the Fe304(111) Surface. The Journal of Physical Chemistry C 2010, 114, 21405-21410.

(9) Sun, Q.-C.; Sims, H.; Mazumdar, D.; Ma, J. X.; Holinsworth, B. S.; O'Neal, K. R.; Kim, G.; Butler, W. H.; Gupta, A.; Musfeldt, J. L.: Optical band gap hierarchy in a magnetic oxide: Electronic structure of NiFe_\{2\}O_\{4\}. Physical Review B 2012, 86.

(10) Šepelák, V.; Baabe, D.; Mienert, D.; Schultze, D.; Krumeich, F.; Litterst, F. J.; Becker, K. D.: Evolution of structure and magnetic properties with annealing temperature in nanoscale high-energymilled nickel ferrite. Journal of Magnetism and Magnetic Materials 2003, 257, 377-386.

(11) Luders, U.; Bibes, M.; Bobo, J. F.; Fontcuberta, J.: Tuning the growth orientation of NiFe2O4 films by appropriate underlayer selection. Applied Physics A 2004, 80, 427-431.

(12) Klewe, C.; Meinert, M.; Boehnke, A.; Kuepper, K.; Arenholz, E.; Gupta, A.; Schmalhorst, J. M.; Kuschel, T.; Reiss, G.: Physical characteristics and cation distribution of NiFe2O4 thin films with high resistivity prepared by reactive co-sputtering. Journal of Applied Physics 2014, 115, 123903.

(13) Kumar, P. V.; Short, M. P.; Yip, S.; Yildiz, B.; Grossman, J. C.: High Surface Reactivity and Water Adsorption on NiFe2O4(111) Surfaces. The Journal of Physical Chemistry C 2013, 117, 5678-5683.

(14) Giannozzi, P.; Baroni, S.; Bonini, N.; Calandra, M.; Car, R.; Cavazzoni, C.; Ceresoli, D.; Chiarotti, G. L.; Cococcioni, M.; Dabo, I.; Dal Corso, A.; de Gironcoli, S.; Fabris, S.; Fratesi, G.; Gebauer, R.; Gerstmann, U.; Gougoussis, C.; Kokalj, A.; Lazzeri, M.; Martin-Samos, L.; Marzari, N.; Mauri, F.; Mazzarello, R.; Paolini, S.; Pasquarello, A.; Paulatto, L.; Sbraccia, C.; Scandolo, S.; Sclauzero, G.; Seitsonen, A. P.; Smogunov, A.; Umari, P.; Wentzcovitch, R. M.: QUANTUM ESPRESSO: a modular and open-source software project for quantum simulations of materials. J Phys-Condens Mat 2009, 21.

(15) Perdew, J. P.; Burke, K.; Ernzerhof, M.: Generalized Gradient Approximation Made Simple. Physical Review Letters 1996, 77, 3865-3868.

(16) Cococcioni, M.; de Gironcoli, S.: Linear response approach to the calculation of the effective interaction parameters in the LDA+U method. Physical Review B 2005, 71.

(17) Vanderbilt, D.: Soft Self-Consistent Pseudopotentials in a Generalized Eigenvalue Formalism. Physical Review B 1990, 41, 7892-7895. 
(18) Chen, J.; Selloni, A.: Electronic states and magnetic structure at the Co304(110) surface: A first-principles study. Physical Review B 2012, 85, 085306.

(19) Mulakaluri, N.; Pentcheva, R.; Scheffler, M.: Coverage-Dependent Adsorption Mode of Water on Fe304(001): Insights from First Principles Calculations. The Journal of Physical Chemistry C 2010, 114, 11148-11156.

(20) Mulakaluri, N.; Pentcheva, R.; Wieland, M.; Moritz, W.; Scheffler, M.: Partial Dissociation of Water on Fe_\{3\}O_\{4\}(001): Adsorbate Induced Charge and Orbital Order. Physical Review Letters 2009, 103, 176102.

(21) Reuter, K.; Scheffler, M.: Composition and structure of the RuO2 surface in an $\mathrm{O} 2$ and CO environment: Implications for the catalytic formation of CO2. Physical Review B 2003, 68, 045407.

(22) Ivanov, V. G.; Abrashev, M. V.; Iliev, M. N.; Gospodinov, M. M.; Meen, J.; Aroyo, M. I.: Short-range B-site ordering in the inverse spinel ferrite NiFe_\{2\}O_\{4\}. Physical Review B 2010, 82.

(23) Madelung, O.; Rössler, U.; Schulz, M.; : Springer Materials 1991, 26, 2621.

(24) Perron, H.; Mellier, T.; Domain, C.; Roques, J.; Simoni, E.; Drot, R.; Catalette, H.: Structural investigation and electronic properties of the nickel ferrite NiFe2O4: a periodic density functional theory approach. Journal of Physics: Condensed Matter 2007, 19, 346219.

(25) Sit, P. H. L.; Car, R.; Cohen, M. H.; Selloni, A.: Simple, Unambiguous Theoretical Approach to Oxidation State Determination via First-Principles Calculations. Inorganic Chemistry 2011, 50, 1025910267.

(26) McFarland, E. W.; Metiu, H.: Catalysis by Doped Oxides. Chemical Reviews 2013, 113, 4391-4427.

(27) Chen, J.; Wu, X.; Selloni, A.: Electronic structure and bonding properties of cobalt oxide in the spinel structure. Physical Review B 2011, 83, 245204.

(28) Mulakaluri, N.; Pentcheva, R.; Wieland, M.; Moritz, W.; Scheffler, M.: Partial Dissociation of Water on Fe_\{3\}O_\{4\}(001): Adsorbate Induced Charge and Orbital Order. Physical Review Letters 2009, 103. 
Table 1. Displacements of the atoms close to a bulk O-vacancy with respect to their positions in the defect-free crystal (Figure 1b). Atoms are labelled as in Figure 1c. Only the atoms closest to the vacancy are considered.

\begin{tabular}{|c|c|c|c|}
\hline & \multicolumn{3}{|c|}{ Displacement $(\AA)$} \\
\hline & $\mathbf{x}$ & $\mathbf{y}$ & $\mathbf{Z}$ \\
\hline $\mathbf{O 2}$ & 0.071 & -0.044 & -0.048 \\
\hline 011 & 0.008 & 0.044 & 0.045 \\
\hline 013 & -0.041 & 0.005 & 0.053 \\
\hline 014 & 0.051 & 0.012 & -0.047 \\
\hline 018 & 0.057 & 0.054 & -0.001 \\
\hline 019 & -0.033 & -0.011 & -0.004 \\
\hline 025 & 0.077 & 0.055 & 0.075 \\
\hline 031 & -0.025 & -0.052 & 0.056 \\
\hline $\mathrm{Fe} 2$ & 0.281 & -0.242 & 0.273 \\
\hline Fe10 & -0.029 & 0.021 & -0.009 \\
\hline Fe13 & -0.036 & 0.021 & -0.033 \\
\hline Ni6 & -0.010 & 0.060 & -0.017 \\
\hline
\end{tabular}


Table 2. Displacements of the atoms in the first three layers of the relaxed (001) surface relative to their positions at the bulk-terminated surface

\begin{tabular}{ccc}
\hline $\begin{array}{c}\text { displacements } \\
\mathbf{A}\end{array}$ & in plane & (001) direction \\
$\mathrm{O} 1$ & 0.098 & 0.026 \\
$\mathrm{O} 2$ & 0.185 & 0.126 \\
$\mathrm{O} 3$ & 0.185 & 0.080 \\
$\mathrm{O} 4$ & 0.085 & 0.108 \\
$\mathrm{Ni} 1$ & 0.026 & 0.024 \\
$\mathrm{Ni} 2$ & 0.017 & 0.062 \\
$\mathrm{Fe} 1$ & 0.049 & 0.036 \\
$\mathrm{Fe} 2$ & 0.042 & 0.196 \\
$\mathrm{Fe} 3$ & 0.062 & 0.082 \\
\hline
\end{tabular}



Figure(s)
Figure 1

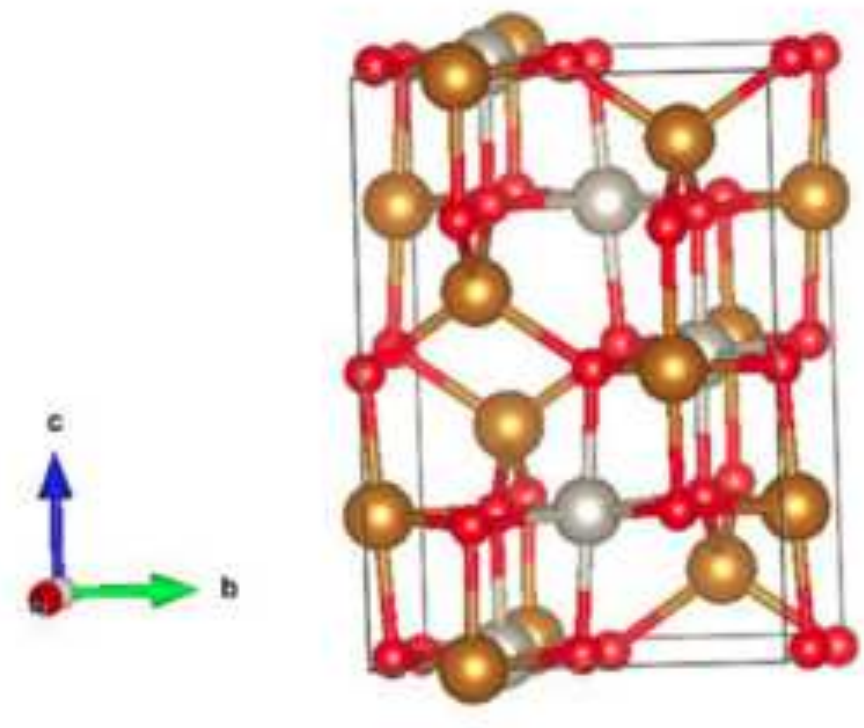

(a)

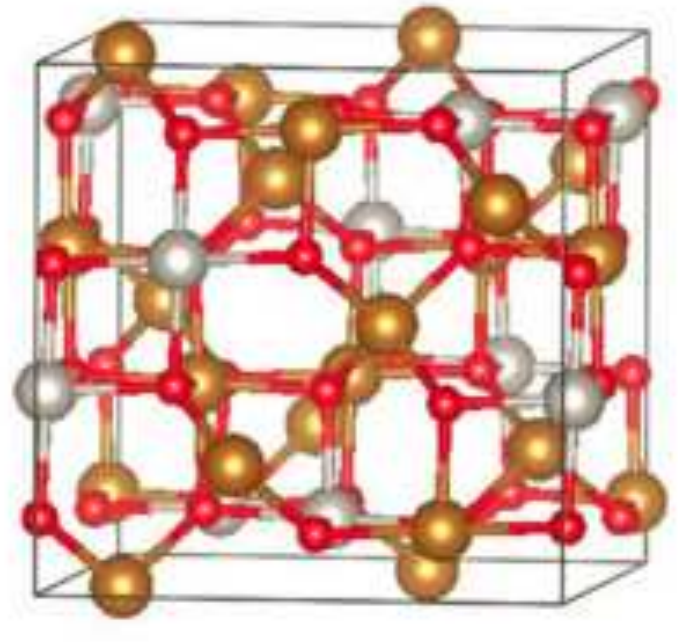

(b)

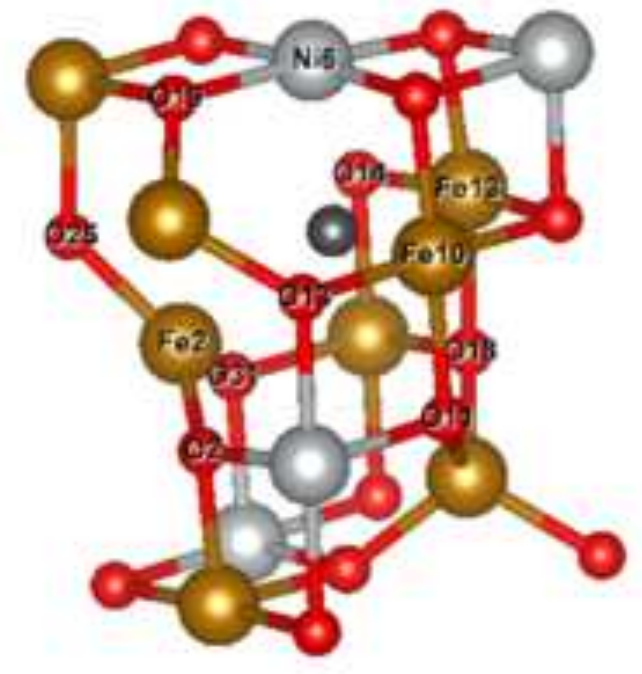

(c) 


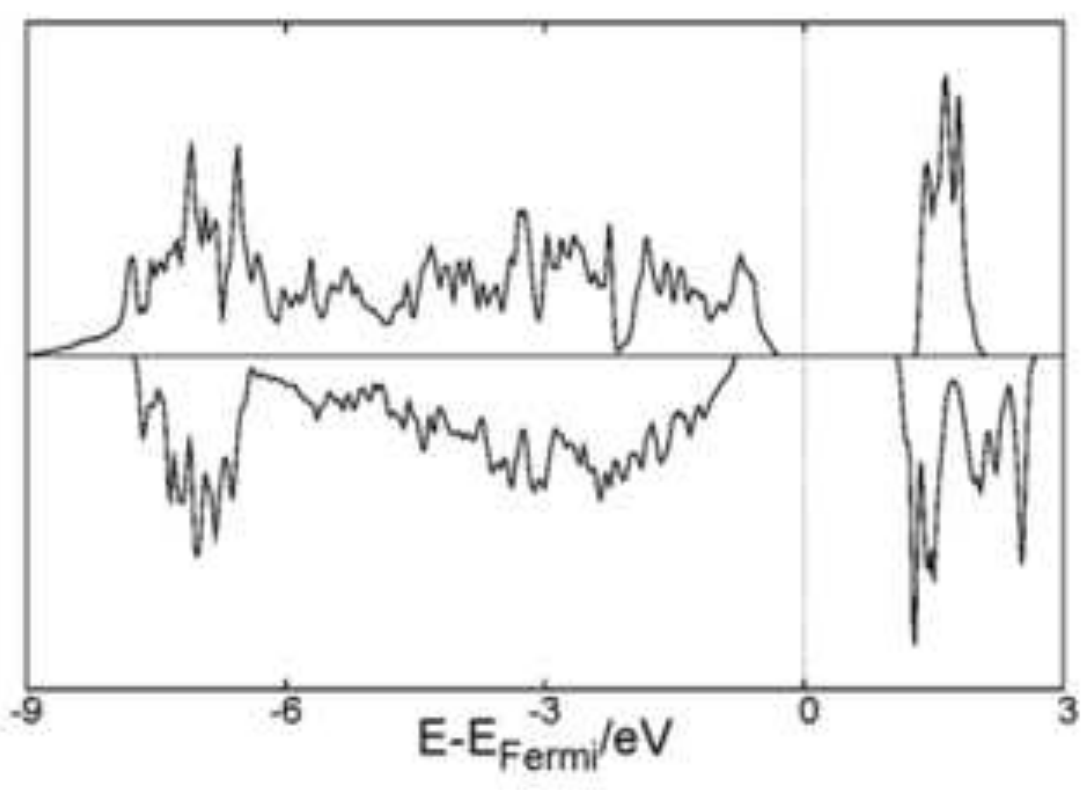

(a)

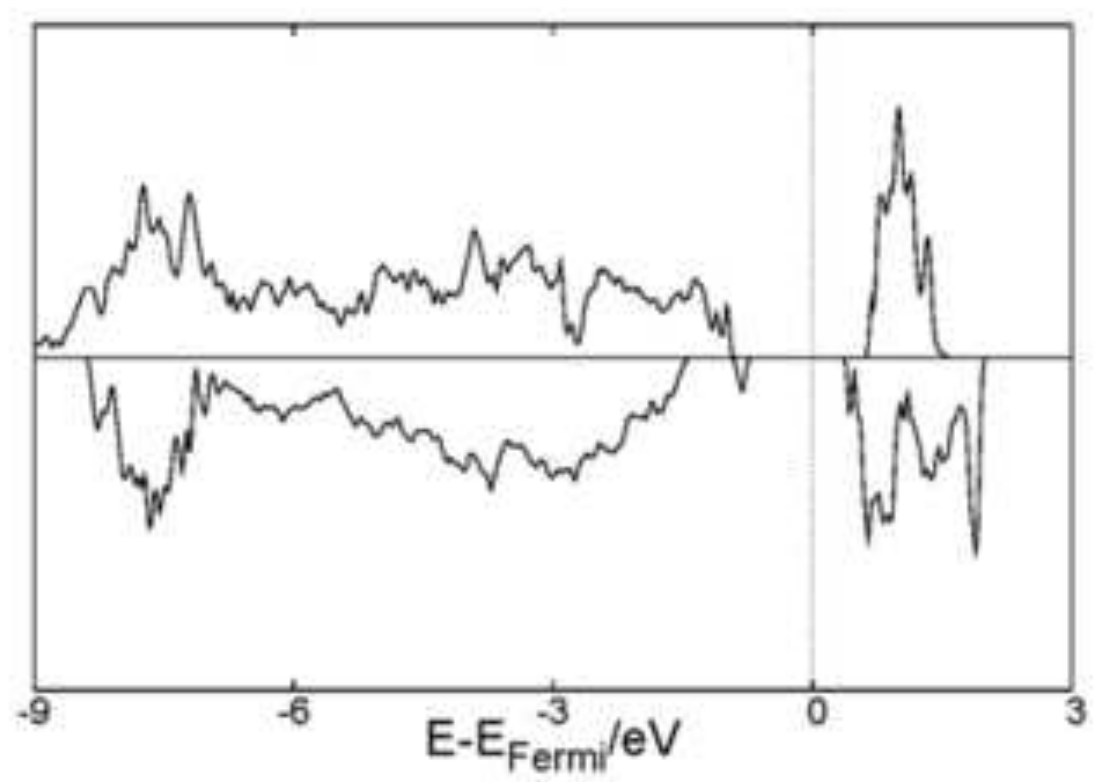

(b) 


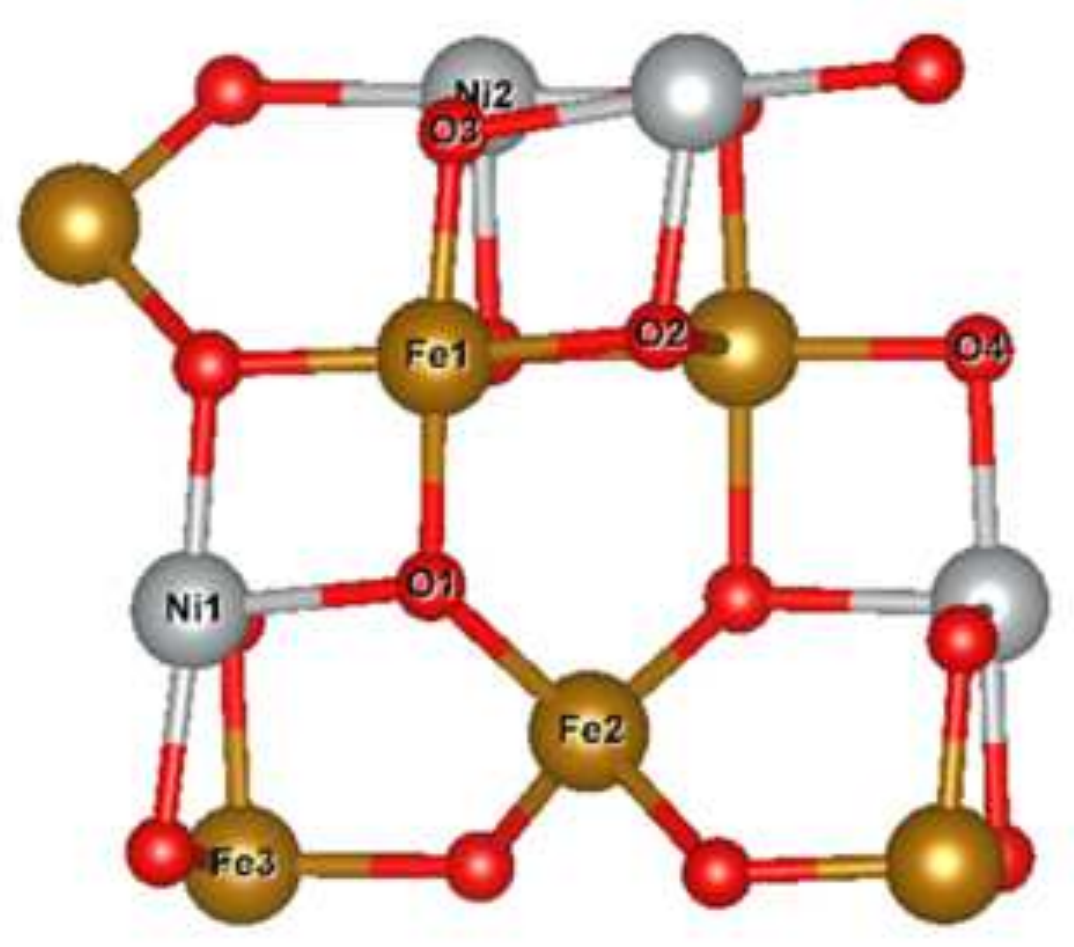

(a)

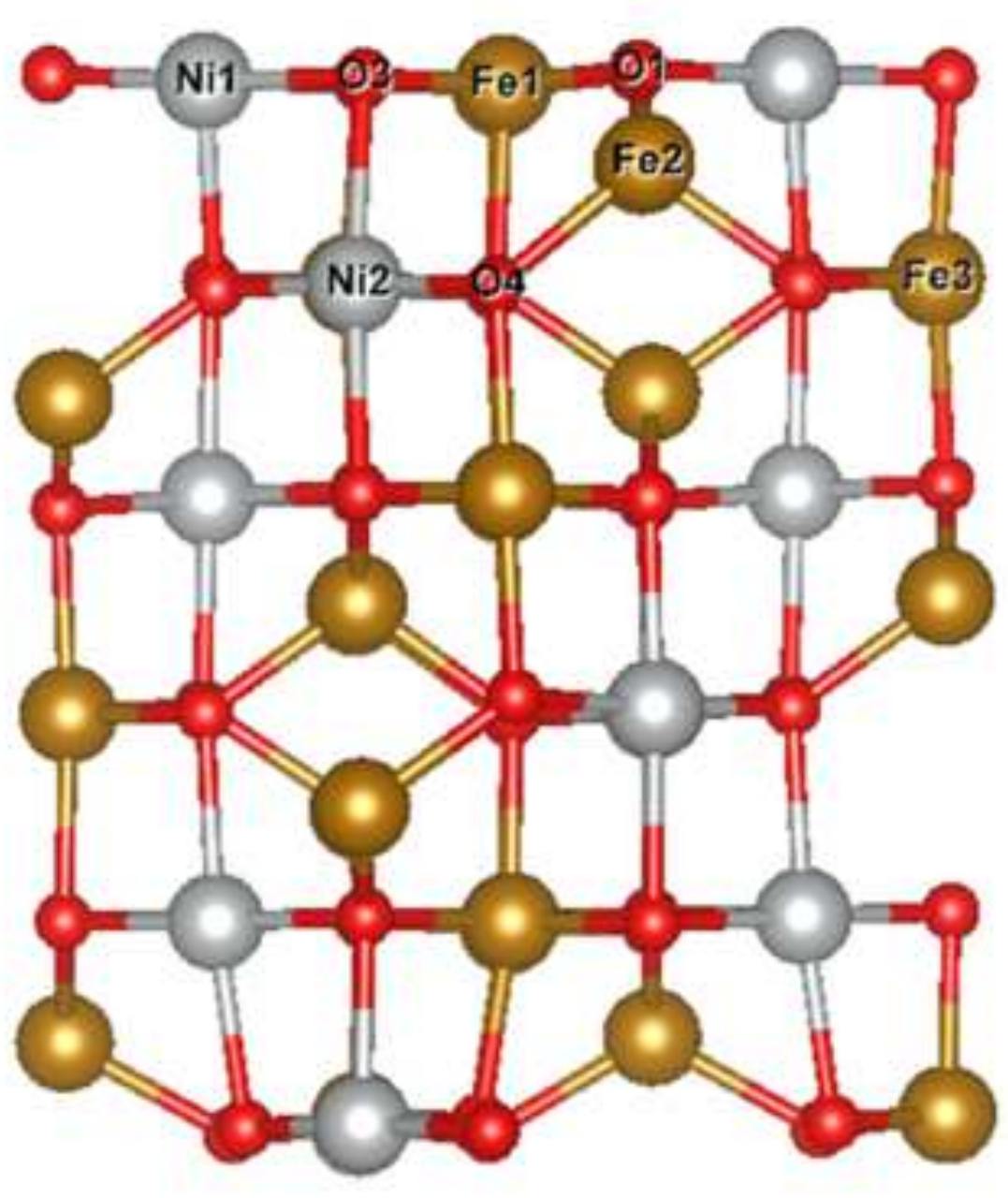

(b) 


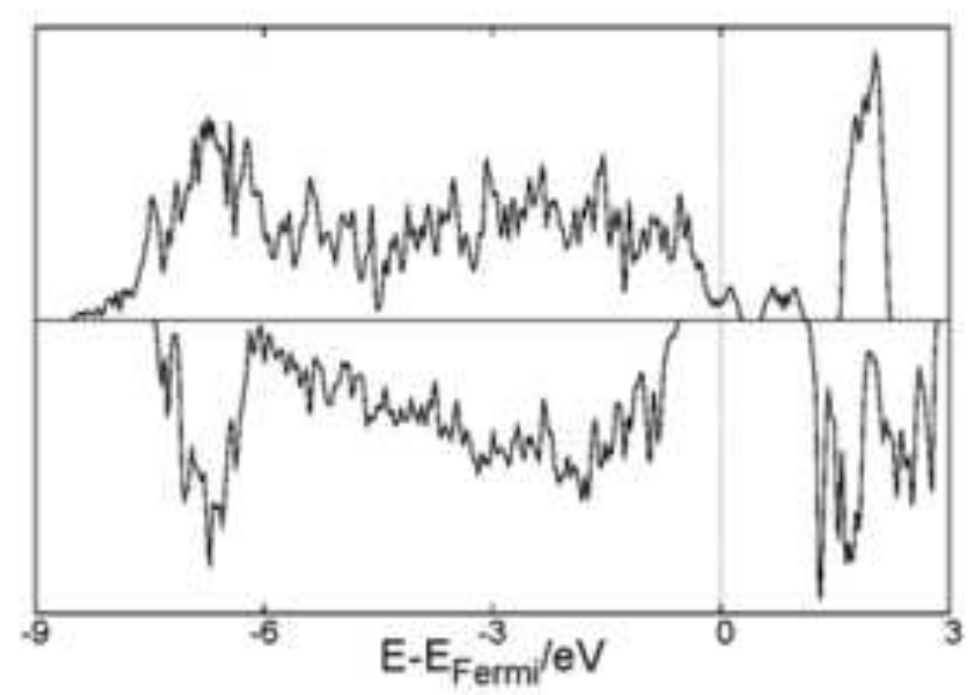

(a)

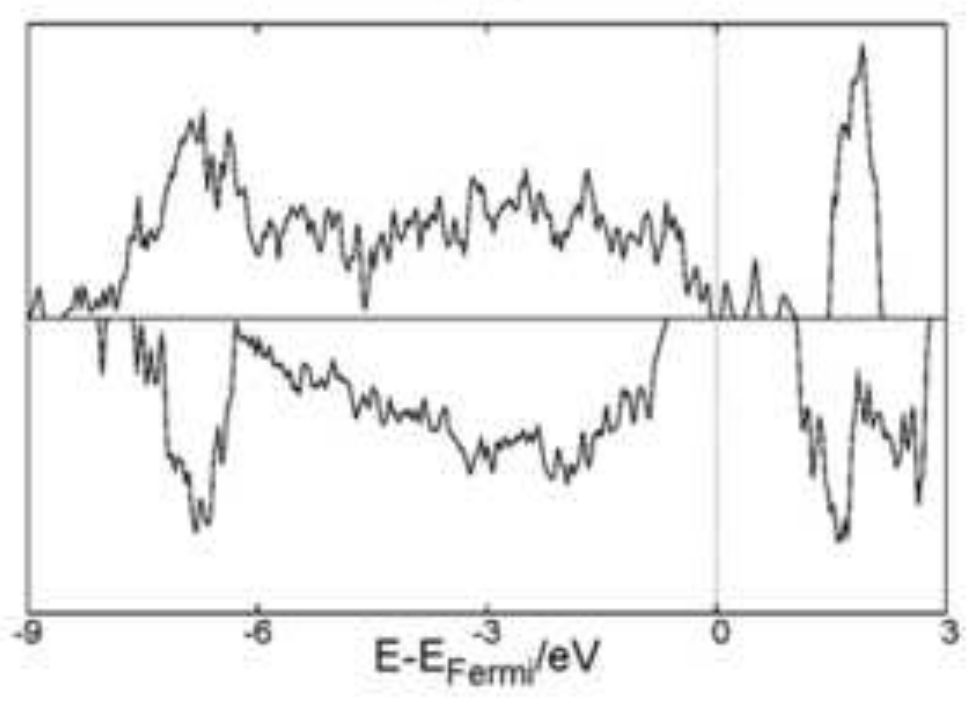

(c)

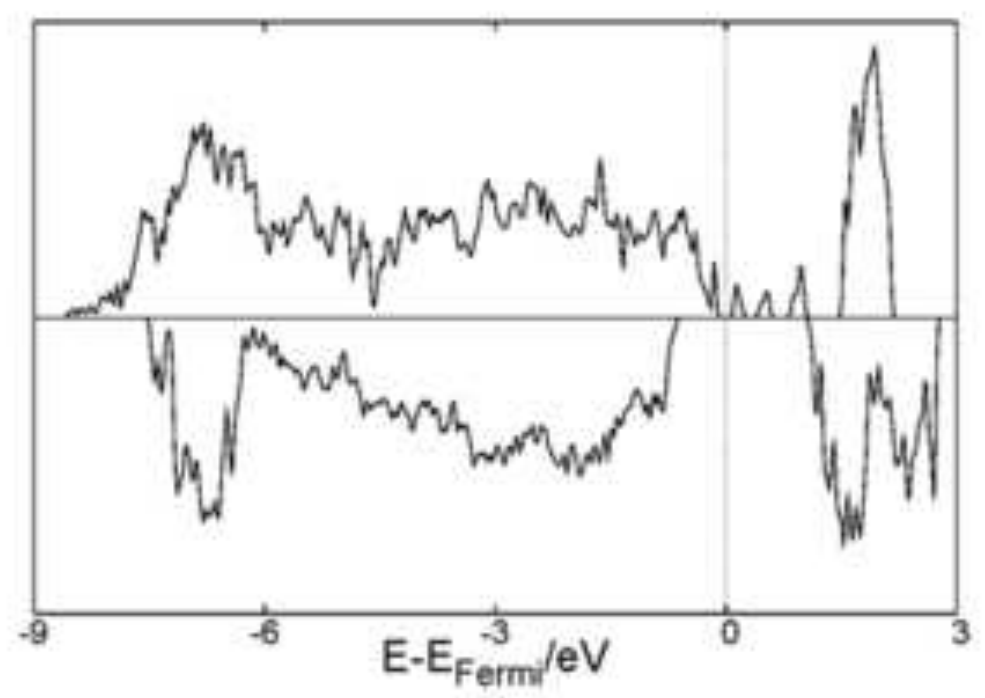

(b)

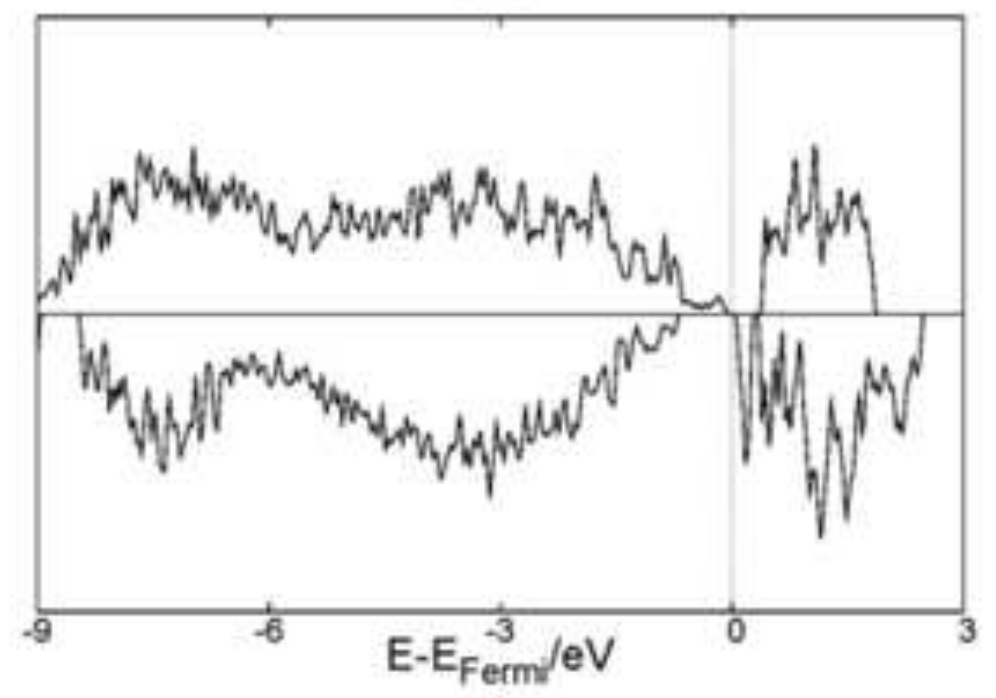

(d) 
Figure 5

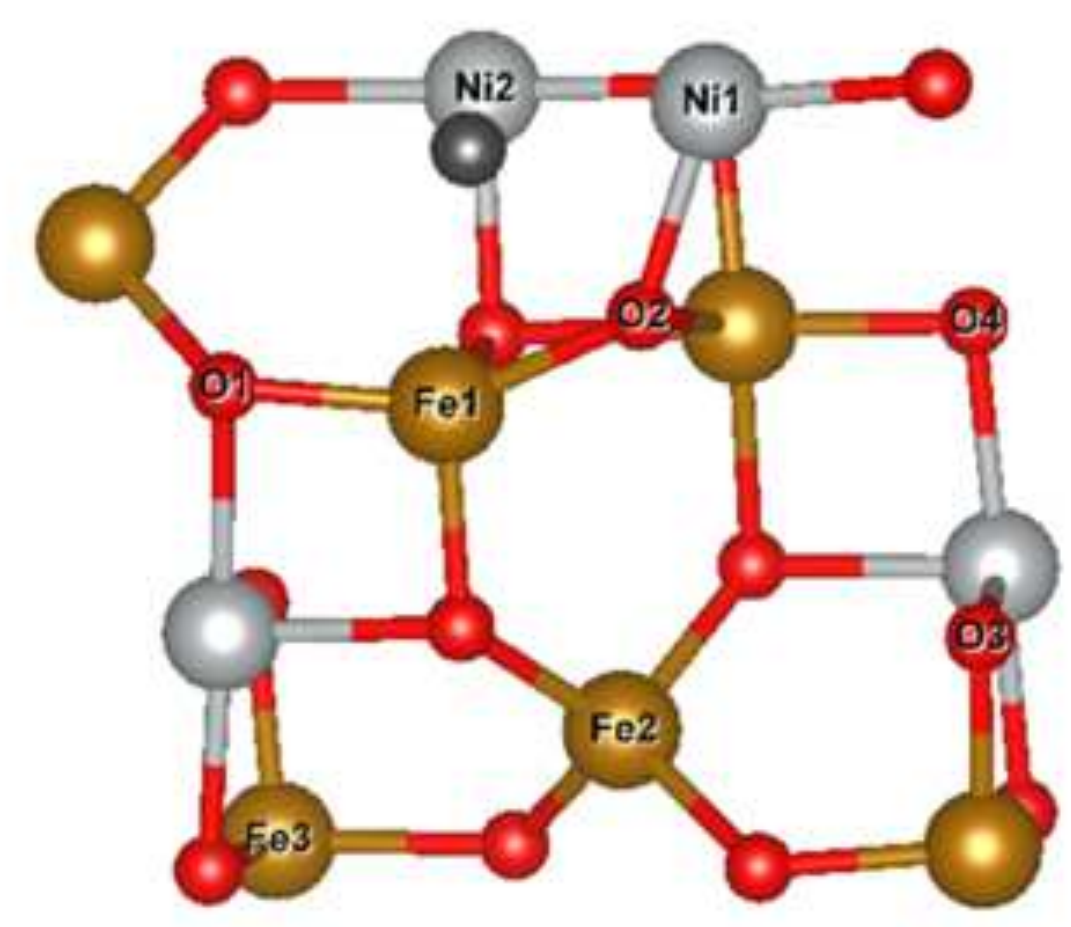

(a)

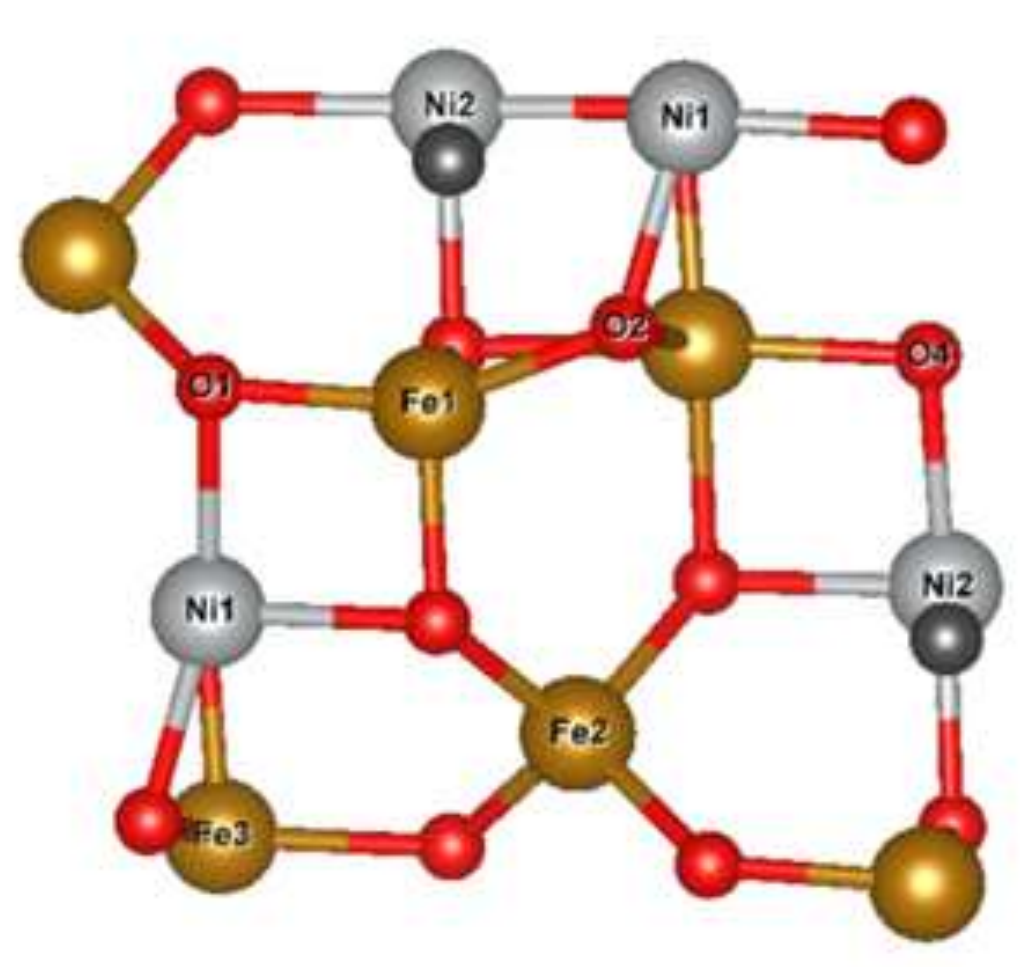

(b) 


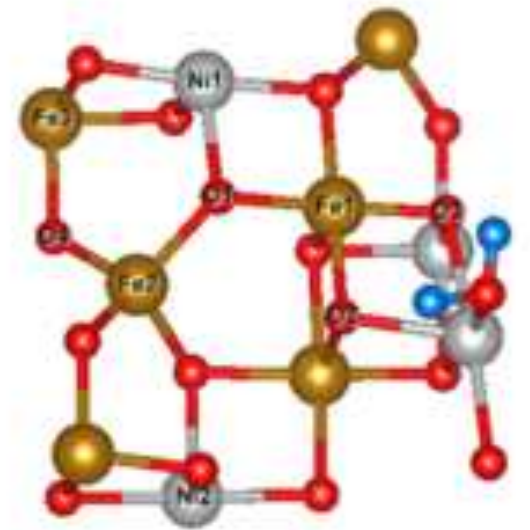

a

$$
E_{\text {ads }}=0.53 \mathrm{eV}
$$

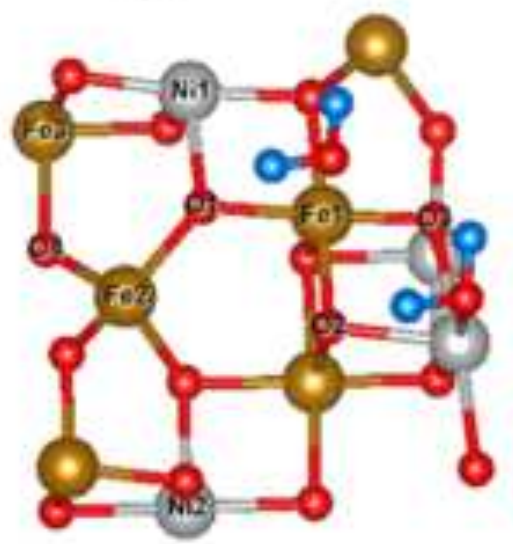

b

$$
E_{\text {ads }}=0.44 \mathrm{eV}
$$
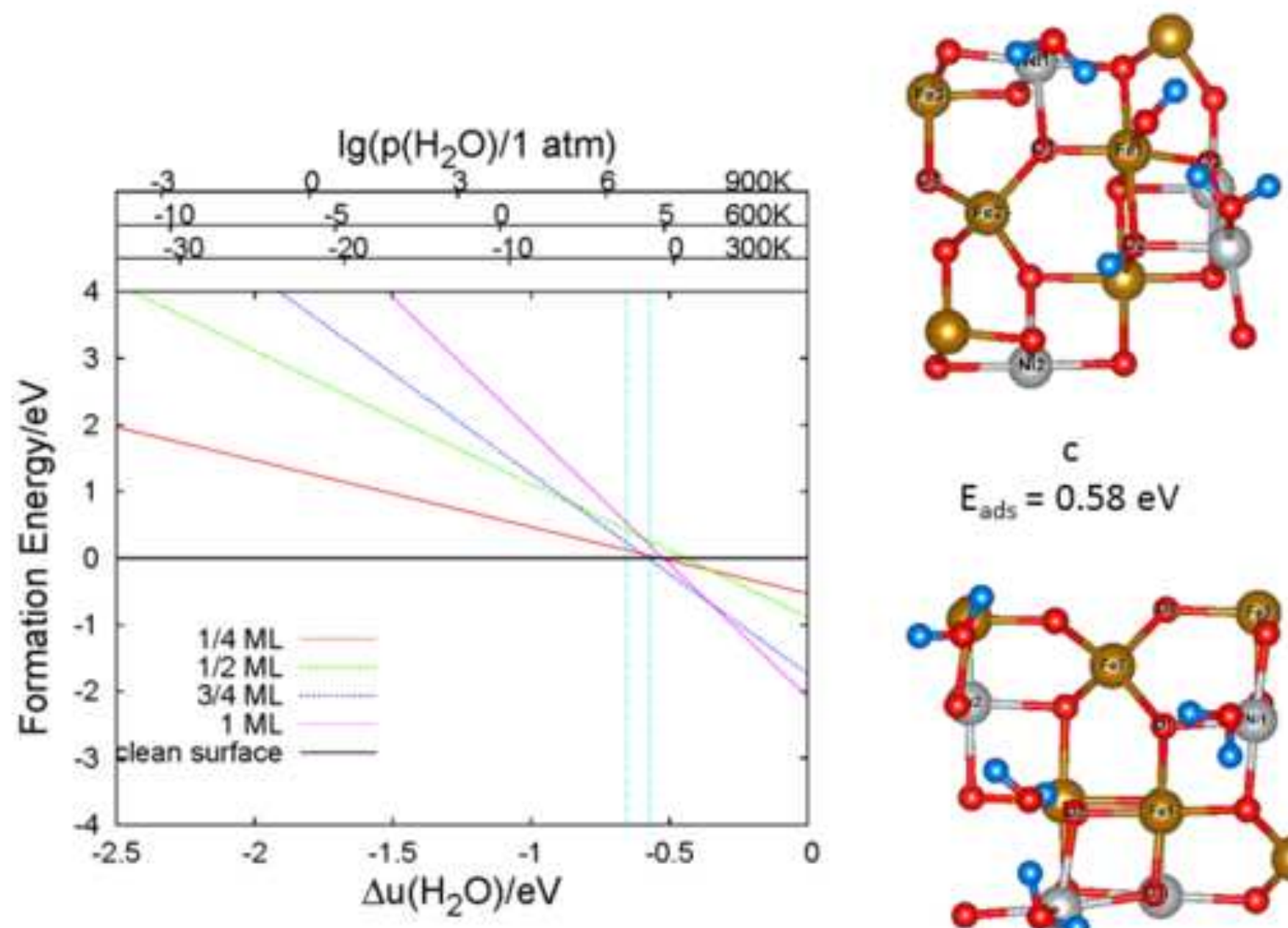

c

$$
E_{a d s}=0.58 \mathrm{eV}
$$

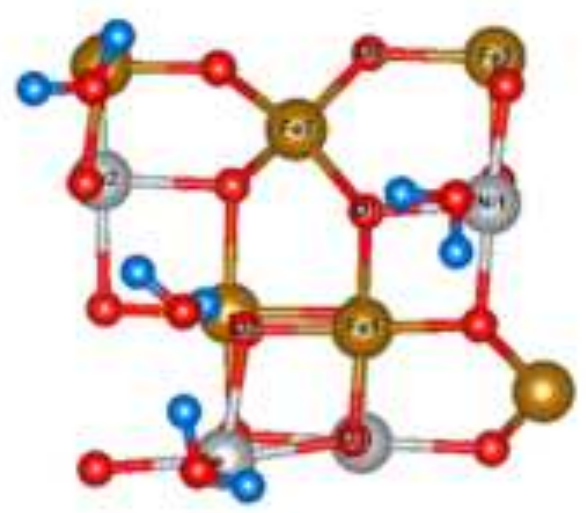

d

$E_{\text {ads }}=0.52 \mathrm{eV}$ 
(a)

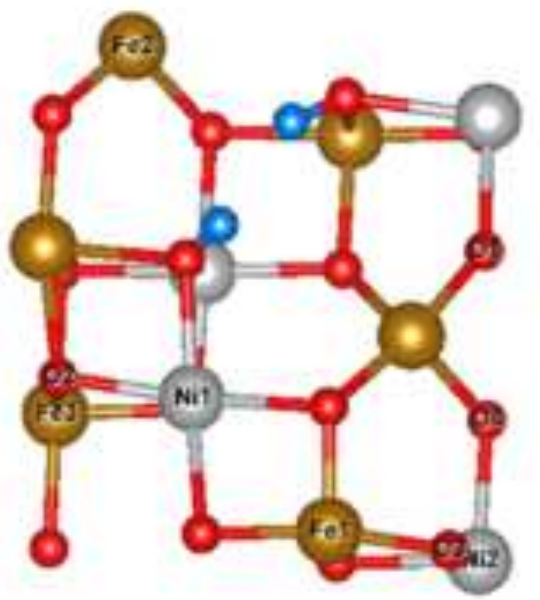

(b)

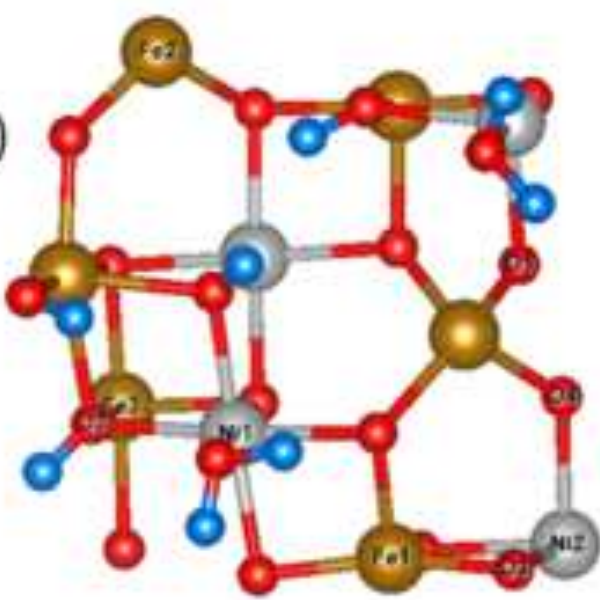

$E_{\text {ads }}=0.70 \mathrm{eV}$ (c)

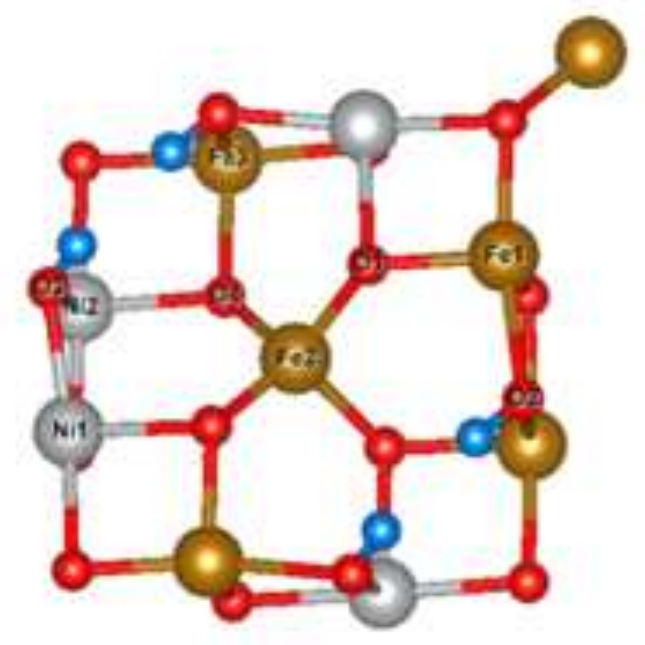

$$
E_{\text {ads }}=1.23 \mathrm{eV}
$$

(d)

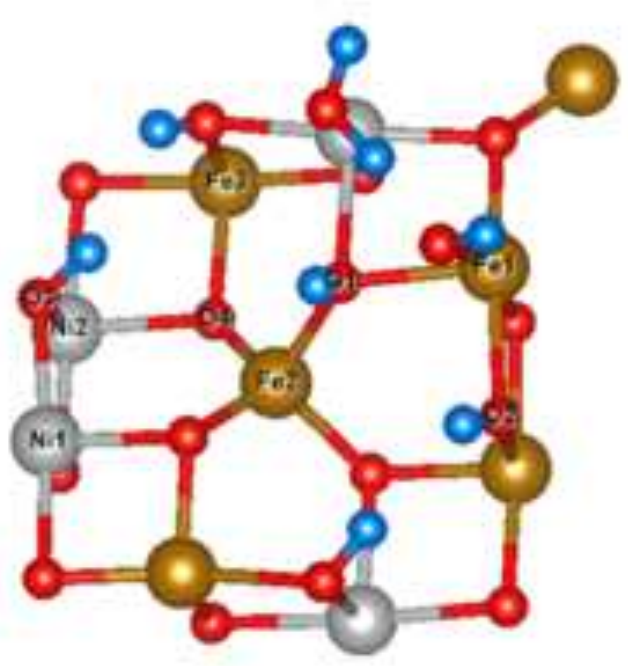

$E_{\mathrm{ads}}=0.86 \mathrm{eV}$ (e)

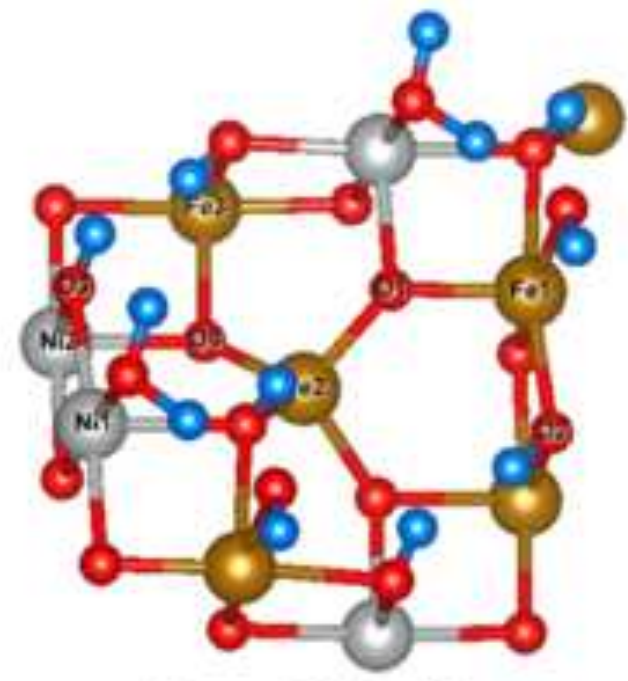

$E_{\text {ads }}=0.72 \mathrm{eV}$ 
Figure 8

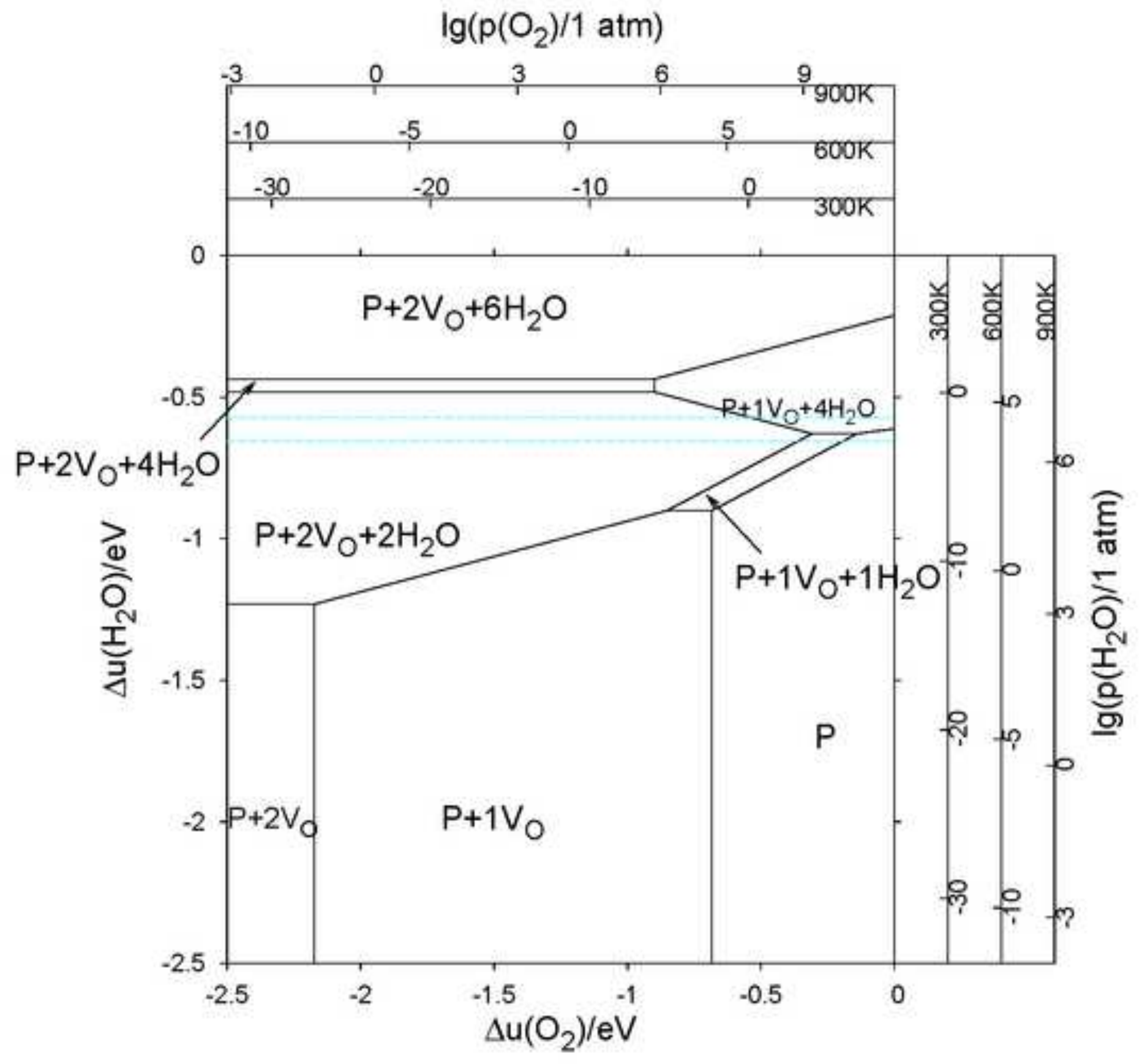

